\title{
Assessment of the calibration performance of satellite visible channels using cloud targets: application to Meteosat-8/9 and MTSAT-1R
}

\author{
S.-H. Ham and B. J. Sohn \\ School of Earth and Environmental Sciences, Seoul National University, Seoul, 151-747, Korea \\ Received: 6 April 2010 - Published in Atmos. Chem. Phys. Discuss.: 17 May 2010 \\ Revised: 15 October 2010 - Accepted: 18 November 2010 - Published: 25 November 2010
}

\begin{abstract}
To examine the calibration performance of the Meteosat-8/9 Spinning Enhanced Visible Infra-Red Imager (SEVIRI) 0.640- $\mu \mathrm{m}$ and the Multi-functional Transport Satellite (MTSAT)-1R 0.724- $\mu \mathrm{m}$ channels, three calibration methods are employed. Total eight months during the 20042007 period are used for SEVIRI, and total seven months during the 2007-2008 period are used for MTSAT-1R. First, a ray-matching technique is used to compare Meteosat- $8 / 9$ and MTSAT-1R visible channel reflectances with the wellcalibrated Moderate Resolution Imaging Spectroradiometer (MODIS) $0.646-\mu \mathrm{m}$ channel reflectances. Spectral differences of the response function between the two channels of interest are taken into account for the comparison. Second, collocated MODIS cloud products are used as inputs to a radiative transfer model (RTM) to calculate Meteosat-8/9 and MTSAT-1R visible channel reflectances. In the simulation, cloud three-dimensional (3-D) radiative effect associated with subgrid variations is taken into account using the lognormal-independent column approximation (LN-ICA) to minimize the simulation bias caused by the plane-parallel homogeneous assumption. Third, an independent method uses the typical optical properties of deep convective clouds (DCCs) to simulate reflectances of selected DCC targets.
\end{abstract}

Although all three methods are not in perfect agreement, the results suggest that calibration coefficients of Meteosat$8 / 90.640-\mu \mathrm{m}$ channels are underestimated by $6-7 \%$. On the other hand, the calibration accuracy of MTSAT-1R visible channel appears to be variable with the target reflectance itself because of an underestimate of calibration coefficient (up to $20 \%$ ) and a non-zero space offset. The results further suggest that the solar channel calibration scheme combining the

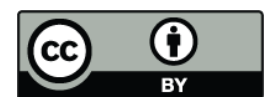

Correspondence to: B. J. Sohn

(sohn@snu.ac.kr) three methods in this paper can be used as a tool to monitor the calibration performance of visible sensors that are particularly not equipped with an onboard calibration system.

\section{Introduction}

Radiometric calibration converts the digital form of raw satellite data into physically meaningful radiances or reflectances. Because meteorological or geophysical parameters are retrieved from converted radiances or reflectances, accurate radiometric calibration is essential for monitoring weather and climate from space.

In the pre-launch stage of the satellite program, the calibration coefficient, which is the ratio for converting the digitized raw counts to radiometric quantities, can be estimated from laboratory experiments (Barnes et al., 1998; Bruegge et al., 1998; Johnson et al., 1999). However, this factor may change after launch in the space environment. Moreover, the sensor degrades with time, implying that operational updates of the calibration coefficient are required for reliable satellite measurements. Onboard calibrators, such as the solar diffuser, can be used for operational calibration (e.g., Barnes et al., 2000; Sakuma et al., 2005; Sun et al., 2005), but satellites are not often equipped with these due to power, weight, and space restrictions (Kriebel and Amann, 1993). To compensate for the limitations of the onboard calibration system, vicarious methods are required to monitor sensor capability.

Inter-satellite calibration is a useful method that has been used in many studies (e.g., Sohn et al., 2000; Heidinger et al., 2002; Minnis et al., 2002a, b; Wu and Sun, 2005; Sohn et al., 2008). Measured radiances (or reflectances) by the target sensor are compared with a well-calibrated reference sensor under ray-matched conditions with the same solar and viewing geometries. However, if spectral characteristics of the

Published by Copernicus Publications on behalf of the European Geosciences Union. 
sensor response functions (SRFs) are considerably different, the spectral relation between the two sensors strongly depends on atmospheric conditions. Nearly operational radiative transfer simulation is required to take instantaneous atmosphere variations into account for the spectral correction. Furthermore, in the case of polar-to-polar orbit satellites, inter-calibration is not practicable because the ray-matching conditions are not easy to find.

On the contrary, vicarious calibration based on the radiative transfer simulation of satellite-level radiance does not require that the two satellites match geometrically. This type of calibration instead requires other auxiliary data, such as surface, atmosphere, aerosol, and cloud parameters, which are needed for specifying inputs to the radiative transfer model (RTM). Because of their nearly invariant surface properties, deserts and ocean regions have been typically used as calibration targets (e.g., Fraser and Kaufman, 1986; Knapp and Vonder Haar, 2000; Govaerts and Clerici, 2004; Govaerts et al., 2004; Martiny et al., 2005; Vermote and Saleous, 2006). A horizontally homogeneous ocean target has stable surface reflectance that can be determined from oceanic pigment concentration, wind speed, and salinity. On the other hand, a desert target exhibits strong surface reflection with small seasonal variations, minimizing the relative contribution of aerosols to radiance at the satellite altitude. However, because of the relatively small reflectance values $(<0.5)$ of these targets, small errors in input data may result in significant relative errors in simulated values, exceeding targeted $5 \%$ of the relative uncertainty (e.g., Arriaga and Schmetz, 1999; Knapp and Vonder Haar, 2000; Govaerts et al., 2001, 2004; Govaerts and Clerici, 2004).

Compared to ocean or desert targets, the intended simulation accuracy can be more easily achieved using cloud targets because uncertainties induced by other input parameters are relatively small, compared to the high reflectance of cloud targets. Moreover, because of the strong reflection by the cloud layer, surface and atmospheric profiles have a negligible impact on the top-of-atmosphere (TOA) simulation, and thus climatological values can be used for specifying surface and atmospheric properties. This is particularly true for deep convective clouds (DCCs) (Vermote and Kaufman, 1995; Govaerts et al., 2001; Hu et al., 2004; Sohn et al., 2009).

In this study, we explore three calibration methods; i.e. a ray-matching method and two cloud modeling methods. The first cloud modeling method uses cloud optical properties obtained from well-calibrated solar channel measurements for calculating the TOA radiances, which are then compared with collocated radiances from target sensors. Moderate Resolution Imaging Spectroradiometer (MODIS) cloud products are used in this study, and thus MODIS solar channel sensors serve as a reference sensor. In the second cloud modeling method, DCC targets are incorporated with the method proposed by Sohn et al. (2009). A more detailed description of the three methods is given in Sect. 2 (Methodology).
Aforementioned three calibration methods are applied to examine the calibration status of visible sensors onboard three geostationary satellites: the European Meteosat- 8 and Meteosat- 9 , located at $3.4^{\circ} \mathrm{W}$ and $0^{\circ} \mathrm{W}$, respectively, and the Japanese Multi-functional Transport Satellite (MTSAT) 1R (hereafter MTSAT-1R), located at $140^{\circ} \mathrm{E}$. Considering that Meteosat-8/9 and MTSAT-1R do not carry an onboard calibration system for the solar channels, but use desert target (Govaerts et al., 2004) and pre-launch calibration (Tahara and Ohkawara, 2006), respectively, this independent assessment will help us understand the current status of operational calibrations employed for those three satellites.

\section{Methodology}

In this study, the MODIS sensor is considered as a reference for calibrating the other visible sensors because the operational calibration of MODIS is well performed (Xiong and Barnes, 2003, 2006). MODIS has 36 spectral channels with wavelengths ranging from 0.41 to $14.5 \mu \mathrm{m}$ aboard both Terra (descending node) and Aqua (ascending node). MODIS radiance data (MOD021/MYD021), provided with a 1-km spatial resolution, are used for the inter-calibration, while MODIS cloud data (MOD06/MYD06), provided with a 1-km or 5$\mathrm{km}$ resolution, are used as RTM inputs for calculating the radiance of target sensors.

Using MODIS measurements, the operational calibrations of the visible channels of the Spinning Enhanced Visible Infra-Red Imager (SEVIRI) aboard Meteosat-8 (before 2007) and Meteosat-9 (after 2007) are examined. SEVIRI has twelve channels within the visible to infrared (IR) spectral region, with a 15-min repeat cycle (Schmetz et al., 2002). In this study we use $0.640-\mu \mathrm{m}$ and $11-\mu \mathrm{m}$ channel measurements with a $4.8-\mathrm{km}$ resolution at nadir. However, because the main signal is coming from a small area centered within a $4.8 \times 4.8 \mathrm{~km}^{2}$ pixel, and SEVIRI samples at a nadir distance of $3 \mathrm{~km}$, the sample size is about $3 \mathrm{~km}$ (Deneke and Roebling, 2010). Radiances at 0.640- $\mu \mathrm{m}$ channels are converted into reflectances using solar irradiances at the band, i.e. $1617.45 \mathrm{~W} \mathrm{~m}^{-2} \mu^{-1}$ for Meteosat- 8 and $1617.03 \mathrm{~W} \mathrm{~m}^{-2} \mu \mathrm{m}^{-1}$ for Meteosat-9 (Govaerts et al., 2006) with the consideration of Sun-Earth distance and solar zenith angle (SZA). Four months of SEVIRI data are used for each satellite, i.e., July 2004, July 2005, July 2006, and one month from 15 October to 14 November 2006 (hereafter denoted as October 2006) for Meteosat-8, and January 2007, April 2007, July 2007, and October 2007 for Meteosat-9. For October 2006 case, 32 images per day at 09:00-17:00 UTC are used, whereas for other monthly periods, 8 images per day at 11:00-13:00 UTC are used. Overall, 1791 and 974 SEVIRI images are used for assessing the calibration status of Meteosat- 8 and Meteosat- 9 , respectively. 


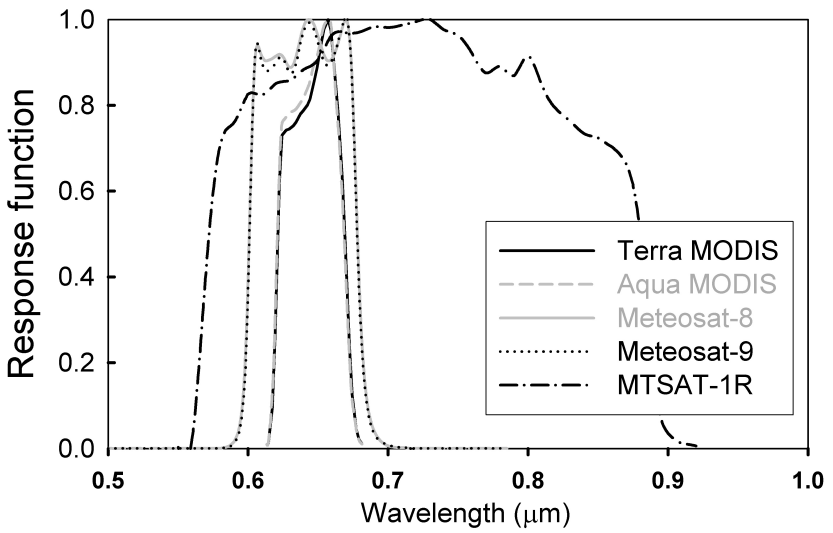

Fig. 1. SRFs of MODIS 0.646- $\mu$ m channels aboard Terra and Aqua, SEVIRI 0.640- $\mu \mathrm{m}$ channels aboard Meteosat- 8 and Meteosat-9, and MTSAT-1R 0.724- $\mu \mathrm{m}$ channel.

The Japanese Advanced Meteorological Imager (JAMI) aboard MTSAT-1R has one visible channel with a 1-km resolution and four IR channels with a 4-km resolution (Japan Meteorological Agency, 2003). Repeat cycle of the full-disk image is one hour, generating 24 images per day, while the observation duration for one image is $24 \mathrm{~min}$. In this study, seven months of data (June 2007, December 2007, JulyNovember 2008) of 0.724- $\mu \mathrm{m}$ and 11- $\mu \mathrm{m}$ channels are used to examine the visible calibration of MTSAT-1R. Nine images per day at 00:00-07:00 UTC and 22:00-24:00 UTC (total 1926 images) are used.

SRFs of MODIS, Meteosat-8/9, and MTSAT-1R visible channels are compared to each other in Fig. 1. MODIS $0.646-\mu \mathrm{m}$ channels show a narrow spectral coverage between $0.60 \mu \mathrm{m}$ and $0.70 \mu \mathrm{m}$, while MTSAT-1R $0.724-\mu \mathrm{m}$ channel shows a broad spectral coverage from $0.55 \mu \mathrm{m}$ to $0.90 \mu \mathrm{m}$. It seems that two MODIS channels aboard Terra and Aqua have negligible spectral differences, and so do two SEVIRI 0.640- $\mu \mathrm{m}$ channels aboard Meteosat- 8 and Meteosat-9.

To examine the calibration status, we employ three methods: an inter-satellite comparison using the ray-matching technique, a radiative transfer calculation over the cloud targets using MODIS cloud products as inputs, and a modeling approach using DCC targets. These three methods are described in detail below.

\subsection{Method 1: the ray-matching technique}

As a reference, measurements from well-calibrated MODIS 0.646- $\mu \mathrm{m}$ channels aboard Terra and Aqua are compared to Meteosat-8/9 SEVIRI 0.640- $\mu \mathrm{m}$ and MTSAT-1R 0.724- $\mu \mathrm{m}$ channel measurements. Since spatial resolutions of MODIS, SEVIRI, and MTSAT-1R visible channels are $1 \mathrm{~km}, 3 \mathrm{~km}$, and $1 \mathrm{~km}$, respectively, all satellite pixel measurements are averaged in a $0.5^{\circ} \times 0.5^{\circ}$ grid format to mitigate differences in spatial resolution as well as to reduce navigation errors and parallax effects. Then the $0.5^{\circ}$-grid box satisfying all ray-matched conditions is used as a calibration target in this method. Time differences of up to 5 min between SEVIRI and MODIS, and MTSAT-1R and MODIS measurements are permitted for this comparison to ensure agreement of solar angles. When matching Meteosat-8/9 with MODIS measurements, the observation time of all pixels in a MODIS granule image is fixed with centered granule observation time. Since the scanning time for one granule is about $5 \mathrm{~min}$, the time allocation used in this study can cause at most $2.5 \mathrm{~min}$ of error. On the other hand, different observation time is applied for each line of Meteosat-8/9 scan image, by considering the full disk image scanned from south to north in about $12 \mathrm{~min}$. By the same token, observation time is defined for each line of MTSAT-1R image, but in this case the image is scanned from north to south in $24 \mathrm{~min}$. The collocated targets are only collected over the ocean to minimize surface influences. Moreover, because visible reflectance is sensitive to both the viewing zenith angle (VZA) and the viewing azimuth angle (VAA), sensor viewing geometries are considered to satisfy thresholds of $5^{\circ}$ for VZA differences and $15^{\circ}$ for VAA differences. Limits of the $\mathrm{SZA} \leq 40^{\circ}$ and $\mathrm{VZA} \leq 40^{\circ}$ are also applied to minimize navigation errors. Note that the collocation is made regardless of the presence of clouds.

Because the SRF determines the magnitude of gas absorption and scattering, cloud extinction, and surface reflectance for the given band, the spectral differences between SRFs should be considered for the intercomparison. To obtain theoretical relations between two sensors, radiative transfer simulations are performed using Santa Barbara Disort Radiative Transfer (SBDART; Ricchiazzi et al., 1998) model. In the simulation, surface type is assumed to be ocean since calibration targets are collected only over ocean. Then oceanic bidirectional distribution function (BRDF) model is used for obtaining surface reflectance with $0.1 \mathrm{mg} \mathrm{m}^{-3}$ of pigment concentration, $5 \mathrm{~m} \mathrm{~s}^{-1}$ of wind speed, and $34.3 \%$ of salinity. Note that the oceanic BRDF model provided in SBDART is nearly the same as the one used in Second Simulation of Satellite Signal in the Solar Spectrum (6S) RTM (Vermote et al., 1997). One difference is that the BRDF in SBDART is independent of wind direction because of the average of 6S BRDFs for all azimuth angles (Ricchiazzi, 2002). For estimating the gas absorption for each channel, Low Resolution Transmission (LOWTRAN) 7-based transmittances (Pierluissi and Peng, 1985) are used with three-term exponential fitting (Ricchiazzi et al., 1998). Temperature, pressure, water vapor, and ozone profiles are described from standard tropical profiles, with an assumption that all collocated targets are located between $20^{\circ} \mathrm{N}$ and $20^{\circ} \mathrm{S}$, for satisfying $\mathrm{SZA} \leq 40^{\circ}$ and $\mathrm{VZA} \leq 40^{\circ}$.

For the cloudy sky, scattering properties of water droplets are obtained from Mie calculations, while scattering properties of ice habits are described from Baum et al. (2005a, $\mathrm{b}$; hereafter Baum's scattering model). Baum's scattering model provides bulk scattering properties of nonspherical 

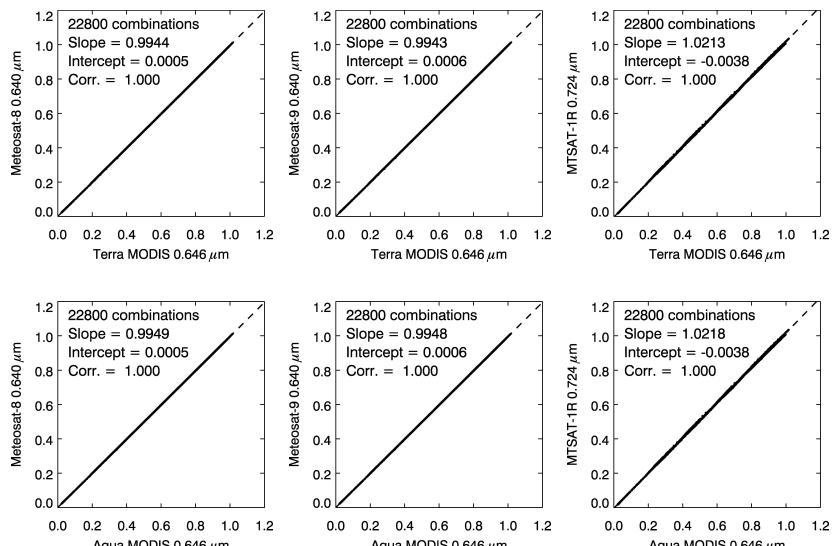

Aqua MODIS $0.646 \mu \mathrm{m}$
MODIS sensors aboard Terra and Aqua are separately related to the reflectances measured by two SEVIRI sensors aboard Meteosat- 8 and Meteosat- 9 and by the MTSAT-1R visible sensor.

$R_{\mathrm{MET} 8,0.640}=0.9944 R_{\mathrm{TERRA}, 0.646}+0.0005$

$R_{\mathrm{MET} 8,0.640}=0.9949 R_{\mathrm{AQUA}, 0.646}+0.0005$

$R_{\text {MET } 9,0.640}=0.9943 R_{\text {TERRA }, 0.646}+0.0006$

$R_{\mathrm{MET} 9,0.640}=0.9948 R_{\mathrm{AQUA}, 0.646}+0.0006$

$R_{\text {MTSAT, } 0.724}=1.0213 R_{\text {TERRA, } 0.646}-0.0038$

$R_{\text {MTSAT }, 0.724}=1.0218 R_{\mathrm{AQUA}, 0.646}-0.0038$

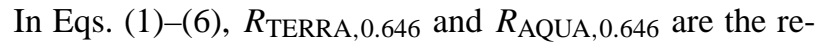
flectances at the MODIS 0.646- $\mu \mathrm{m}$ channels aboard Terra and Aqua, respectively; $R_{\text {MET8,0.640 }}$ and $R_{\text {MET9,0.640 }}$ are reflectances at the SEVIRI $0.640-\mu \mathrm{m}$ channels aboard Meteosat- 8 and Meteosat-9, respectively; and $R_{\text {MTSAT, } 0.724}$ is the reflectance at the MTSAT-1R 0.724- $\mu$ m channel. Because MODIS 0.646- $\mu \mathrm{m}$ and SEVIRI 0.640- $\mu \mathrm{m}$ channels have a similar spectral coverage, where the gas absorption and cloud property are nearly constant with wavelength, reflectances at these channels are expected to be similar, as indicated by the slope of 0.99 and near-zero intercept. On the other hand, the slightly different MTSAT-1R $0.724-\mu \mathrm{m}$ channel reflectances are expected due to a much broader SRF coverage of the MTSAT-1R channel.

Using Eqs. (1)-(6), the observed MODIS reflectances are converted to reflectances at the channel of interest, with a MODIS-equivalent accuracy. Therefore, if the given sensor is calibrated with the same accuracy as that of MODIS, the observed reflectances would be very similar to those obtained from the regression equations.

\subsection{Method 2: use of MODIS cloud products as inputs to RTM}

As in Method 1, all satellite measurements are converted into $0.5^{\circ}$-grid data for the collocation between two satellites over ocean. Then the $0.5^{\circ}$-grid box satisfying all threshold conditions is used as a calibration target in this method. The calibration targets are selected if the observation time difference is less than $5 \mathrm{~min}$. Note that difference in sensor viewing angles is not counted, while threshold conditions of $\mathrm{SZA} \leq 40^{\circ}$ and $\mathrm{VZA} \leq 40^{\circ}$ are applied to minimize navigation errors and three-dimensional (3-D) radiative effects. After applying MODIS cloud mask information, only the $0.5^{\circ}$-grid boxes that are filled entirely with cloud pixels are considered. Finally, grid boxes showing a COT smaller than 5 are discarded to minimize ocean surface influences.

For selected cloud grid targets, sensor-reaching reflectances are simulated using collocated MODIS-derived cloud products, such as COT, cloud effective radius, cloud 

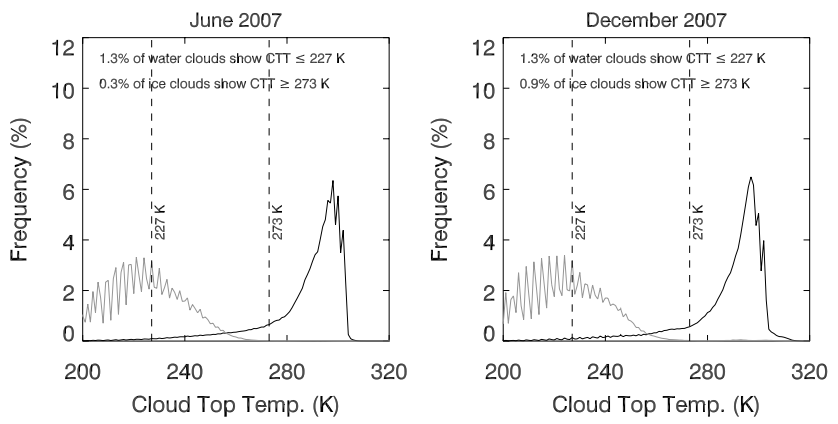

Fig. 3. Frequency distributions of MODIS-derived CTT for water (black solid line) and ice (grey solid line) clouds at a 5-km resolution for June 2007 (left panel) and December 2007 (right panel) over $100^{\circ} \mathrm{E}-180^{\circ} \mathrm{E}, 40^{\circ} \mathrm{N}-40^{\circ} \mathrm{S}$ area.

top pressure (CTP), and cloud top temperature (CTT). To determine the dominant cloud phase at a $0.5^{\circ}$-grid box, grid-averaged CTT is used. The threshold conditions of CTT are prepared based on two-month (June and December 2007) of MODIS data over $100^{\circ} \mathrm{E}-180^{\circ} \mathrm{E}, 40^{\circ} \mathrm{N}-$ $40^{\circ} \mathrm{S}$ area. In Fig. 3, using MODIS cloud phase products ("Cloud_Phase_Infrared") provided at a 5-km resolution, frequency distributions of CTT are separately obtained for ice and water clouds. For both periods, ice clouds show a high peak frequency around $220 \mathrm{~K}$, while water clouds show a peak at $300 \mathrm{~K}$. Since most of water clouds satisfy CTT $>227 \mathrm{~K}$, while only $1.3 \%$ of water clouds are colder than $227 \mathrm{~K}, \mathrm{CTT} \leq 227 \mathrm{~K}$ may be used as a stable criterion for selecting pure ice clouds. Moreover, considering that ice clouds are rarely warmer than $273 \mathrm{~K}(<1 \%$ of total ice clouds), CTT $\geq 273 \mathrm{~K}$ can be used as a water cloud criterion. After determining cloud phase, Mie and Baum scattering models are used for simulating water and ice clouds, respectively. Clouds with CTT between $227 \mathrm{~K}$ and $273 \mathrm{~K}$ are discarded because of the difficulty in specifying optical properties of potentially mixed-phase clouds. Note that ice clouds may have larger simulation uncertainties than water clouds due to nonspherical particle shapes assumed in Baum's scattering model. Therefore, only water clouds are used in the simulation for the Meteosat-8/9 calibration because these targets appear abundant. For the MTSAT-1R, however, due to the lack of water cloud targets over the observation domain, both water and ice cloud targets are used for the simulation.

After determining the cloud phase, the scattering properties of the cloud, such as extinction efficiency, single scattering albedo, and scattering phase function, are obtained by interpolating parameters from the Mie or Baum scattering models for the given effective radius of the particle and spectral channel. Consequently, COT at a specific spectral channel is obtained by scaling MODIS COT at $0.646 \mu \mathrm{m}$ with extinction efficiencies obtained from the scattering model. The cloud top height is obtained from the MODIS CTP, and then the cloud geometrical depth is set $1 \mathrm{~km}$. The assumption of geometrical depth is reasonable, according to the sensitivity test in Ham et al. (2009) (in Appendix B), which demonstrated that cloud vertical shape had negligible effects on the visible channel simulation.

Because the spectral bands of SEVIRI or MTSAT-1R visible channels are located over an insignificant gas absorption band, standard tropical profiles are used to specify the atmospheric conditions. In order to justify the use of standard tropical profiles representing the atmospheric status, we conduct a sensitivity test. The use of mid-latitude summer (MLS) profiles instead of tropical profiles suggests that the profile change can cause uncertainties in reflectances up to $1.0 \%$ and $1.1 \%$ for SEVIRI and MTSAT-1R visible channels, respectively, when COT $=5$, cloud top height $=2 \mathrm{~km}$, and cloud base height $=1 \mathrm{~km}$ are used (for a thin and low cloud). Moreover, with the same cloud conditions, we test how TOA reflectances are sensitive to seasonally varying ozone amounts by allowing $\pm 10 \%$ of variations of tropical ozone profile [i.e., tropical ozone profile $\mathrm{O}_{3}(\mathrm{z}), \mathrm{O}_{3}(\mathrm{z}) \times 1.1$, $\mathrm{O}_{3}(\mathrm{z}) \times 0.9$ ], while other variables are kept constant. Results indicate that up to $0.6 \%(0.3 \%)$ of SEVIRI (MTSAT-1R) reflectance can be changed by different ozone profiles. Relatively small changes in SEVIRI and MTSAT-1R reflectances in sensitivity test justify the use of fixed atmospheric profiles at most within a $1 \%$ uncertainty range. In addition, surface reflectances are specified using the oceanic BRDF model that is the same as used in Method 1, since cloud targets are chosen over the ocean.

With the given inputs, the SBDART model is used to calculate the channel reflectances, implemented with 20 streams. The SBDART model considers multiple scattering by atmospheric particles under the assumption of a planeparallel atmosphere. Therefore, errors caused by the neglect of 3-D radiative effects may be included in the simulation of $0.5^{\circ}$-grid reflectances. In the next two subsections, 3-D effects of the cloud on the simulation are quantitatively examined by dividing the 3-D effects into two parts: the effect associated with horizontal variations and the effect associated with horizontal radiative interactions. Finally, the first term is taken into account using the approach of Oreopoulos and Davies (1998b). The second term is not counted in this method because its contribution appears negligible. In this approach we follow the terms used in other studies (e.g., Cahalan et al., 1994a, b).

It is interesting to note that the performance of Methods 1 and 2 can be related to each other because cloud products are from the same MODIS radiances. However, Method 2 appears to have its own advantage, considering Method 2 has less limitation in choosing the spectral region for channels. This is because the RTM proposed in the Method 2 incorporates any shape of SRFs, and moreover, water or ice cloud properties within the given spectral band can be easily obtained from Mie calculation or Baum's hyperspectral data (Baum et al., 2007), respectively. On the other hand, in Method 1, comparison between two channels is feasible 

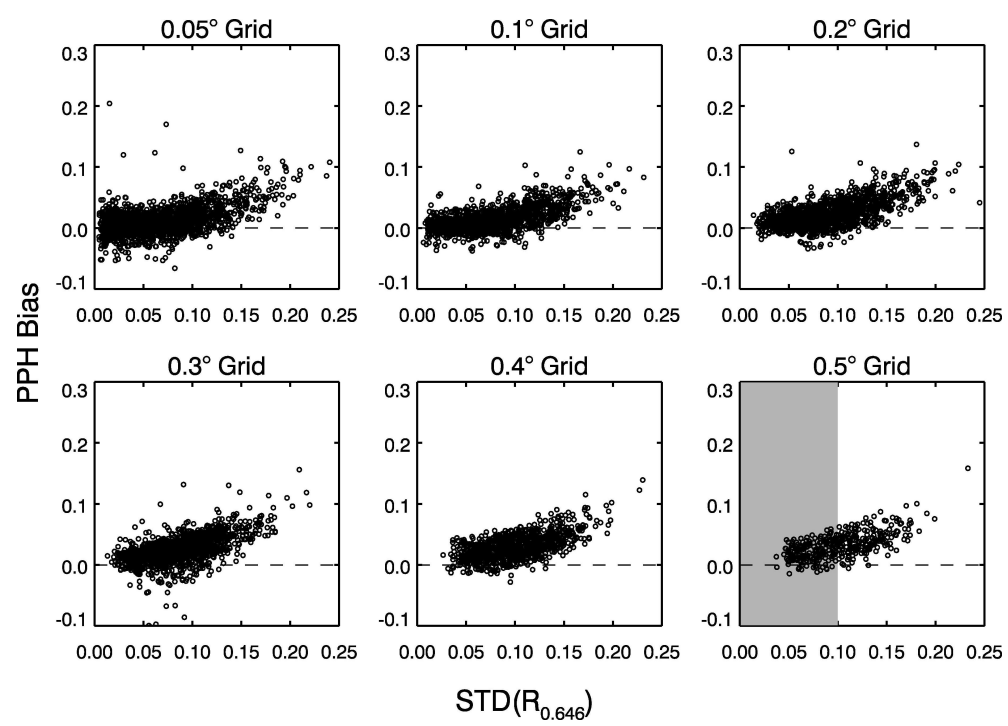

Fig. 4. Scatter plots of estimated PPH bias using MODIS one-month (July 2004) data for six grid sizes of $0.05^{\circ}, 0.1^{\circ}, 0.2^{\circ}, 0.3^{\circ}, 0.4^{\circ}$, and $0.5^{\circ}$ vs. subgrid variability $\left[\operatorname{STD}\left(R_{0.646}\right)\right]$.

only if strong gas absorption is avoided and two channels are located in the similar spectral region. In Method 2, simple tropical profiles are used for the RTM simulations since SRFs of Meteosat-8/9 and MTSAT-1R visible channels are located in the negligible gas absorption band. However, information on atmospheric profiles such as Atmospheric Infrared Sounder (AIRS) profiles can certainly improve the accuracy of Method 2 in particular for the channels whose SRF is located over the strong gas absorption band.

\subsubsection{Lognormal-independent column approximation (LN-ICA) to take into account 3-D effects associated with subgrid variations}

In Method 2, which uses MODIS cloud products, pixel data are averaged and reformatted into $0.5^{\circ} \times 0.5^{\circ}$ grid data for the collocation. If the gridded MODIS cloud parameters are used to describe characteristics of the cloud's optical properties without considering subgrid variations, simulation errors can be induced because of the nonlinear relationship between COT and reflectance, as indicated by the previous studies (e.g., Cahalan et al., 1994a; Barker, 1996; Oreopoulos and Davies, 1998a; Calin et al., 2002). To consider the influence of simulation errors related to subgrid variations, the plane-parallel homogeneous (PPH) bias is described as follows (Cahalan et al., 1994a):

$\Delta R_{\mathrm{PPH}}=R_{\mathrm{PPH}}-R_{\mathrm{ICA}}=R\left(\frac{1}{N} \sum_{i=1}^{N} \tau_{i}\right)-\frac{1}{N} \sum_{i=1}^{N} R\left(\tau_{i}\right)$

$=R(\langle\tau\rangle)-\langle R(\tau)\rangle$

where $\Delta R_{\mathrm{PPH}}$ is the PPH bias; $R_{\mathrm{PPH}}$ is the reflectance at a grid box from the PPH assumption; $R_{\mathrm{ICA}}$ is the reflectance at a grid box from the independent column approximation (ICA) by considering the subgrid variations; $\tau_{i}$ is COT at the $i$ th subgrid point; $N$ is the number of subgrid points in a grid box; and the operator $<>$ represents a grid averaging. In this study, to estimate the magnitude of the PPH bias, measured MODIS reflectance data are used along with MODIS cloud products. Note that MODIS-retrieved cloud field could have certain biases because one-dimensional (1-D) RTM is used for the retrieval, while cloud shadow and illumination effects are ignored. However, the shadow and illumination are actually the results of the second 3-D effect (horizontal radiative interactions), and the effect will be investigated separately in the next part whether it produces systematic biases or not. At this point we only focus on the simulation biases caused by ignoring horizontal inhomogeneity in the grid box, and we assume that MODIS-derived cloud field represents general features of cloud horizontal distribution [two-dimensional (2-D) field] of nature. Moreover, since observation geometry of COT and viewing geometry of simulation are the same, the 3-D effects associated with shadow and illumination would be cancelled out.

The estimation of PPH biases is firstly based on the fact that MODIS visible channel reflectance at a pixel point can be accurately calculated within a $3 \%$ of uncertainty level using cloud parameters of MODIS products (Ham et al., 2009). This suggests that grid-mean values of simulated and measured reflectances are expected to be nearly the same. Therefore, we replace the second term in Eq. (7) with measured grid reflectances to represent ICA reflectance, i.e.:

$$
\begin{aligned}
& \Delta R_{\mathrm{PPH}} \cong R_{\text {sim }}\left(\frac{1}{N} \sum_{i=1}^{N} \tau_{i}\right)-\frac{1}{N} \sum_{i=1}^{N} R_{\text {obs }}\left(\tau_{i}\right) \\
& =R_{\text {sim }}(\langle\tau\rangle)-\left\langle R_{\text {obs }}(\tau)\right\rangle
\end{aligned}
$$


where subscripts "sim" and "obs" denote simulated and observed reflectances, respectively. This is an efficient way to get the ICA reflectance because only average of measured pixel reflectances in a grid box is needed. On the contrary, for obtaining ICA reflectance from the radiative simulation, all subpixel reflectances in one grid box need to be simulated individually. For example, cloud reflectances at about 2500 subpixel points should be modeled for the estimation of ICA reflectance at a $0.5^{\circ}$-grid box from MODIS-measured cloud fields. Realistic approach may be impossible because of the computational burden, and thus we later adopt an approximate ICA method for SEVIRI and MTSAT-1R channel calibrations.

Using Eq. (8), PPH biases at the MODIS 0.646- $\mu \mathrm{m}$ channel are estimated for a one-month period (July 2004) over equatorial Atlantic region $\left(40^{\circ} \mathrm{W}-40^{\circ} \mathrm{E}, 40^{\circ} \mathrm{N}-40^{\circ} \mathrm{S}\right)$, and the results are shown in Fig. 4. In this estimation, overcast cloud grid boxes observed only over ocean are used for COT $\geq 5$. The standard deviation (STD) of the $0.646-\mu \mathrm{m}$ reflectance at each grid box $\left[\operatorname{STD}\left(R_{0.646}\right)\right]$ is used as an indicator of the subgrid variability, while grid size varies from $0.05^{\circ}$ to $0.5^{\circ}$. The PPH bias clearly increases with the subgrid variability; that is, if the $0.05^{\circ}$-grid is used, $\mathrm{PPH}$ bias is between -0.05 and 0.05 for $\operatorname{STD}\left(R_{0.646}\right) \leq 0.1$, but increases up to 0.1 for $\operatorname{STD}\left(R_{0.646}\right)=0.2$. On the other hand, the overall magnitude of PPH biases is larger for the $0.5^{\circ}$ grid than for the $0.05^{\circ}$ grid. Therefore, we recommend using a smaller grid size showing smaller subgrid variability for minimizing PPH biases. Because the conversion into $0.5^{\circ}$-grid data is indispensable for the collocation between two satellites in Method 2, we apply a threshold condition of $\operatorname{STD}\left(R_{0.646}\right) \leq 0.1$ to choose homogenous cloud targets. However, even if the homogeneity check is applied to select targets, positive PPH biases are still expected, as marked as a grey box in Fig. 4, implying that subgrid variability should be counted for accurate simulation.

Considering ideal ICA calculation is hard to accomplish due to computation time, in this study we adopt the lognormal independent column approximation (LN-ICA) method (Oreopoulos and Davies, 1998b) as an approximation method to resolve subgrid variability. This method derives a grid reflectance from integration of subgrid reflectances using a probability density function (PDF) of COT; that is:

$R_{\mathrm{LN}-\mathrm{ICA}}=\int R(\tau) p_{\mathrm{LN}}(\tau) d \tau$

where $R_{\mathrm{LN}-\mathrm{ICA}}$ is the reflectance at a grid box from the LNICA method; $R(\tau)$ is the reflectance when COT is $\tau$; and $p_{\mathrm{LN}}(\tau)$ is the fitted LN function representing a PDF of COT. To construct $\mathrm{LN}$ function with given mean $[\mathrm{E}(\tau)]$ and variance $[\mathrm{V}(\tau)]$ of COT at each grid box, a method of moments
Table 1. Monthly mean differences of simulated $0.5^{\circ}$-grid reflectances from observed grid reflectances at the MODIS 0.646- $\mu \mathrm{m}$ channel. PPH and LN-ICA methods are used to simulate grid reflectance. The uncertainty ranges are estimated with a $68 \%$ confidence level ( \pm one standard deviation).

\begin{tabular}{lcr}
\hline Period & PPH Method & LN-ICA Method \\
\hline JUL 2004 & $4.6 \pm 3.2 \%$ & $0.8 \pm 2.7 \%$ \\
JUL 2005 & $3.9 \pm 3.4 \%$ & $0.3 \pm 3.0 \%$ \\
JUL 2006 & $2.9 \pm 3.7 \%$ & $-0.5 \pm 3.6 \%$ \\
OCT 2006 & $1.1 \pm 2.4 \%$ & $-2.4 \pm 2.1 \%$ \\
JAN 2007 & $1.8 \pm 3.2 \%$ & $-1.7 \pm 2.8 \%$ \\
APR 2007 & $2.9 \pm 2.3 \%$ & $0.3 \pm 2.1 \%$ \\
JUL 2007 & $2.9 \pm 2.9 \%$ & $-0.6 \pm 2.4 \%$ \\
OCT 2007 & $2.3 \pm 1.9 \%$ & $-0.8 \pm 1.7 \%$ \\
\hline
\end{tabular}

(MOM) is also used as follows:

$$
\begin{aligned}
& p_{\mathrm{LN}}(\tau)=\frac{1}{\sigma \tau \sqrt{2 \pi}} \exp \left[-\frac{(\ln \tau-\mu)^{2}}{2 \sigma^{2}}\right] \text { where } \\
& \mu=\ln [E(\tau)]-\frac{1}{2} \ln \left[1+\frac{V(\tau)}{E(\tau)^{2}}\right] \text { and } \sigma^{2}=\ln \left[\frac{V(\tau)}{E(\tau)^{2}}+1\right] .
\end{aligned}
$$

After obtaining simplified PDF of COT with an LN function, the grid reflectance can be estimated using Eq. (9). For the efficient integration with relatively small integral points, Gaussian points and weights are employed. Since five Gaussian points produce nearly the same integration results as those from eight Gaussian points (not shown), five Gaussian points are employed in this study. Finally, grid reflectances in the LN-ICA method can be obtained as follows:

$$
\begin{aligned}
& R_{\mathrm{LN}-\mathrm{ICA}} \simeq \int_{\tau_{\min }}^{\tau_{\max }} R(\tau) p_{\mathrm{LN}}(\tau) d \tau \\
& \simeq \frac{\tau_{\max }-\tau_{\min }}{2} \sum_{i=1}^{5} w_{i} p_{\mathrm{LN}}\left(\tau_{i}\right) R\left(\tau_{i}\right)
\end{aligned}
$$

where $\tau_{\min }=E(\tau)-2 \sqrt{V(\tau)} ; \tau_{\max }=E(\tau)+2 \sqrt{V(\tau)} ; \tau_{i}=$ $0.5\left(\tau_{\max }-\tau_{\min }\right) x_{i}+0.5\left(\tau_{\max }+\tau_{\min }\right)$; and $x_{i}$ and $w_{i}$ are $i$ th Gaussian point and weight, respectively.

To examine how efficiently the LN-ICA method removes PPH bias, the method is applied to an eight-month period of MODIS data over equatorial Atlantic region $\left(40^{\circ} \mathrm{W}-\right.$ $40^{\circ} \mathrm{E}, 40^{\circ} \mathrm{N}-40^{\circ} \mathrm{S}$ ). Table 1 summarizes the differences between simulated and observed MODIS 0.646- $\mu \mathrm{m}$ channel reflectances at the $0.5^{\circ}$-grid box. For the comparison, both PPH and LN-ICA methods are used to simulate grid reflectance. When the PPH assumption is used, the monthly means of differences are between $+1.1 \%$ and $+4.6 \%$ (the second column of Table 1), while the differences range between $-2.4 \%$ and $+0.8 \%$ when the LN-ICA method is used (the third column of Table 1). By using the LN-ICA method, most of the positive biases appear to be removed and there is no dominant sign of simulation biases against the measured 
reflectances. In October 2006, LN-ICA method produces slightly larger simulation biases compared to PPH method probably because of the cases that PDFs of observed COTs are irregularly shaped, and thus LN functions cannot fit the original curves of COT PDFs. Except this period, overall magnitude of simulation biases from LN-ICA method is smaller than that from PPH method, suggesting that the LNICA method can be successfully used for resolving subgrid variations in $0.5^{\circ}$-grid calculation.

\subsubsection{3-D effects associated with horizontal radiative interactions}

Although the subgrid variation is resolved using the LN-ICA method, simulation biases can still remain if we ignore horizontal radiative interactions. This is particularly true for 1D RTM, in which reflectance is simulated independently at a column point (i.e., ICA approximation), ignoring interactions between contiguous columns. Moreover, as previously discussed, MODIS cloud products used for RTM inputs in Method 2 are also retrieved from 1-D RTM, which can introduce biased calibration results by 3-D effects associated with radiative interactions. Therefore, the Monte Carlo (House and Avery, 1969; Marchuk et al., 1980) approach is considered to quantitatively examine the influence of the horizontal radiative interaction. The Monte Carlo model generates several numbers of photons in 3-D domain and simulates scattering and absorption events for each photon. In this study we use GRIMALDI (Scheirer and Macke, 2003) Monte Carlo model, and consider 100000 photons $\times$ total column number in the domain. Since the horizontal photon movement induces horizontal radiative interactions, both full 3-D and ICA modeling are available by turning on or off the horizontal movement option that is available in GRIMALDI. Then ICA bias is defined as the difference between ICA and full 3-D modeling results (Cahalan et al., 1994b), i.e.:

$\Delta R_{\mathrm{ICA}}=R_{\mathrm{ICA}}-R_{3-\mathrm{D}}$

where $\Delta R_{\mathrm{ICA}}$ is the ICA bias; and $R_{\mathrm{ICA}}$ and $R_{3-\mathrm{D}}$ are simulated reflectances from ICA and full 3-D methods, respectively. The ICA bias is estimated only for nadir view (VZA $=0^{\circ}$ ) because horizontal photon movement produces a horizontal shift of cloud image for slanted view $\left(\mathrm{VZA}>0^{\circ}\right)$, and in this case direct comparison is not possible between ICA and 3-D simulation results.

As boundary conditions, Lambertian surface is assumed with albedo of 0.05 , while a periodic condition is assumed at the side boundaries. In the calculation domain, only clouds are regarded as extinction media, while no aerosol and gas are assumed. Because of the ignored gas absorption and nearly the same cloud properties over the visible spectrum, the simulation results show a small spectral dependence. Therefore, fixed wavelength of $0.646 \mu \mathrm{m}$ is used in the calculation, expecting similar results to SEVIRI or MTSAT-1R visible channels. In addition, even if we expect changes in the overall magnitude of cloud reflectance when different cloud phase or particle effective radius are used, the effect on horizontal interactions such as photon leakages and illumination-shadow contrasts appears to be very small. Therefore cloud phase is fixed to be ice and particle size is assumed to be $20 \mu \mathrm{m}$.

To obtain statistics of ICA biases, several case studies are performed with cloud shapes from CloudSat measurements. CloudSat 2B-GEOPROF data provide 2-D images of the vertical cross-section of clouds along satellite paths (set as Xaxis) with a vertical resolution of $240 \mathrm{~m}$ and a horizontal resolution of $1.1 \mathrm{~km}$. To construct the 3-D cloud structures from observed 2-D profiles, the 2-D profile is extended infinitely along a cross-track direction (set as y-axis). Thus variation of cloud structure is not allowed along the cross-track direction. For the given cloud structure, a fixed extinction coefficient of $0.005 \mathrm{~m}^{-1}$ is used to calculate the total columnar COT between cloud top and base heights. The extinction coefficient of $0.005 \mathrm{~m}^{-1}$ is not based upon measurements but is arbitrarily chosen. However, CloudSat-derived cloud top/base heights and a fixed extinction coefficient of $0.005 \mathrm{~m}^{-1}$ are able to produce COTs between 0 and 80 , which are in the typical range of MODIS COT measurements. Therefore, we think that the use of fixed coefficient of $0.005 \mathrm{~m}^{-1}$ may produce plausible COT fields, from which 3-D effects can be examined. In addition, many studies pointed out that cloud morphology gives much larger influences on ICA biases, compared to extinction variation in the cloud layer (Loeb et al., 1998; Marshak et al., 1998; Varnai and Davies, 1999; Varnai, 2000). Therefore, a fixed extinction coefficient is used to examine general features of ICA biases, while cloud shape is described from satellite measurements.

Of the one-month CloudSat observations collected during January 2007, four cases that exhibit different cloud types are chosen. Figure 5 shows cloud vertical shapes and COT values for the chosen cases. The first, second, third, and fourth cases are hereafter referred to as CS1, CS2, CS3, and CS4, respectively. CS1 shows a mesoscale convective system (MCS) with about $800-\mathrm{km}$ size. CS2 and CS3 show broken and multilayered clouds with scales of 200-400 km. CS4 includes a DCC system with a scale of $1000 \mathrm{~km}$.

In Fig. 6, ICA biases of the four cases are estimated at two SZAs: SZA $=0^{\circ}$ and SZA $=40^{\circ}$. For the case of SZA $=40^{\circ}$, a solar azimuth angle (SAA) is set at $90^{\circ}$, meaning that sunlight enters from the positive $\mathrm{x}$-axis. ICA biases with different SAAs (e.g., $0^{\circ}, 180^{\circ}$, and $270^{\circ}$ ) are not displayed here because similar behaviors are shown to those for SAA = $90^{\circ}$. Larger fluctuations of ICA biases are found for SZA = $40^{\circ}$ (right panels, Fig. 6) compared to SZA $=0^{\circ}$ (left panels, Fig. 6). This is because cloud shadows and illuminated areas are generated for slanted sunlight in 3-D modeling results, whereas those phenomena do not appear in ICA modeling results. Moreover, compared to CS1 and CS4, CS2 and CS3 show larger fluctuations of ICA biases. These are likely due to bumpy cloud shapes and smaller horizontal cloud scales, 

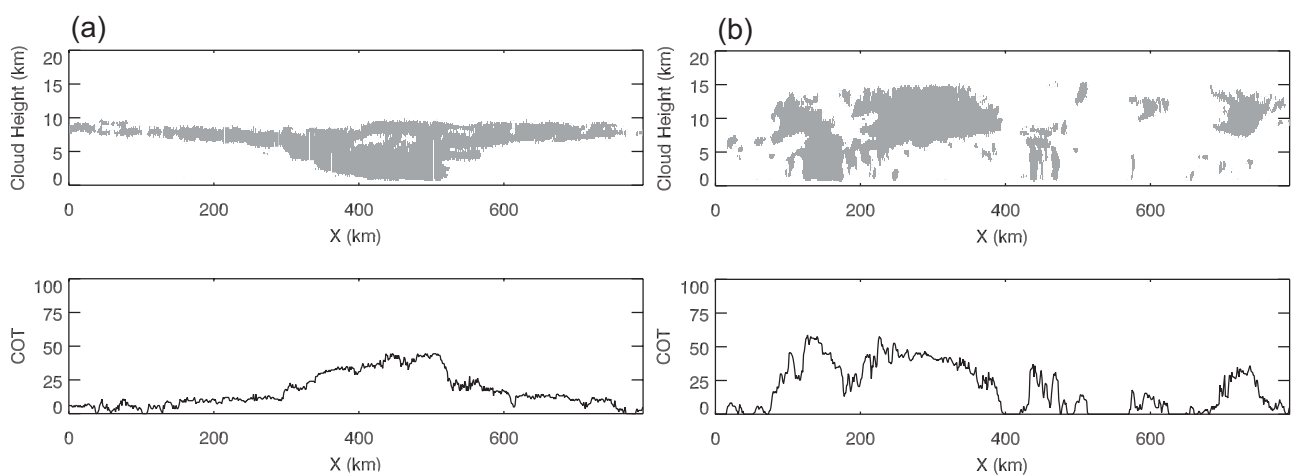

(c)
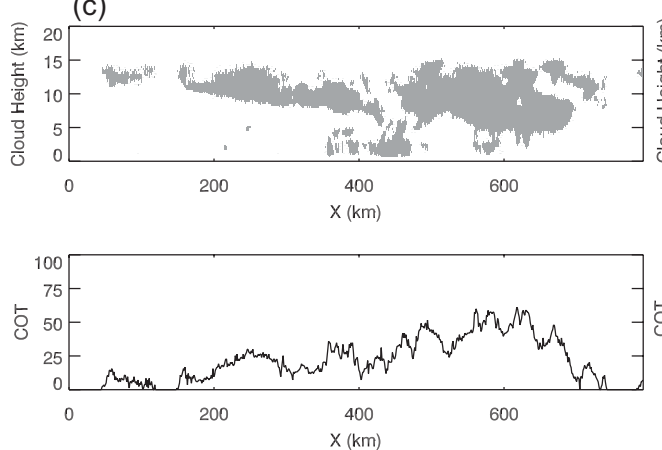

(d)
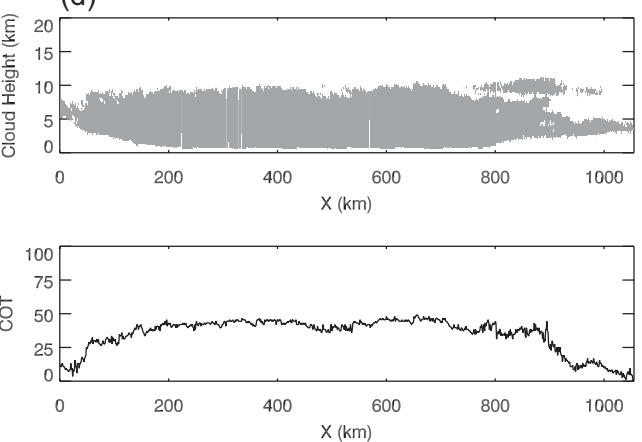

Fig. 5. Distribution of cloud vertical shape and the related COT for (a) CS1, (b) CS2, (c) CS3, and (d) CS4 cloud types.

producing strong cloud shadow-illumination contrasts and photon exchange between cloud and clear regions. Therefore, ICA biases can be minimized once plane-type cloud targets are chosen under small SZAs.

It is also interesting to note that even if there are large fluctuations of ICA bias, the mean of ICA biases is always close to zero ( $\leq 0.02$, Fig. 6), regardless of cases and solar angles. This indicates that horizontal radiative interactions do not cause systematic simulation errors (or calibration errors) but only random errors that can be reduced by spatial or temporal averaging.

In Table 2, spatial averaging is performed for every 50 pixels over the $\mathrm{x}$-axis, which results in comparable scale to $0.5^{\circ}$ grid size used in calibration Method 2. Comparing maximum and STD of ICA biases in Table 2 with those found in Fig. 6, fluctuation of ICA biases appears to be dramatically reduced from the 50-pixel averaging. When only spatially homogeneous targets (i.e. CS1 or CS4) are selected on the basis of criterion of $\operatorname{STD}\left(R_{0.646}\right) \leq 0.1$, the influence of ICA bias for $\mathrm{SZA}=40^{\circ}$ may be $0.005-0.007$ with standard deviations of $0.007-0.016$ (i.e. $\leq 2 \%$ of absolute reflectances). In conclusion, ICA biases may be neglected in Method 2 because of their random distributions and small magnitudes. Note that the ICA biases are estimated with only four types of cloud shapes in this study, and thus the magnitudes of actual ICA biases could be different. However, considering that spatial mean of ICA biases is always negligibly small regardless of the cloud shape in this case study, we can expect that averaged ICA biases converge to zero once sufficient number of calibration targets are included. Instantaneous peaks of ICA biases can be smoothed out in this case.

\subsection{Method 3: use of deep convective clouds (DCCs)}

A detailed description of developed and tuned DCC method for MODIS is provided by Sohn et al. (2009). Briefly, DCCs overshooting the tropical tropopause layer (TTL) are selected from MODIS observations when the observed IR brightness temperatures at $11-\mu \mathrm{m}$ channel $\left(\mathrm{TB}_{11}\right) \leq 190 \mathrm{~K}$. Moreover, two types of homogeneity checks are applied to exclude targets extending to the cloud edge. Pixels are selected when the STD of the visible reflectance of the surrounding $9 \times 9$ pixels normalized by their mean value is less than 0.03 , and the STD of $\mathrm{TB}_{11}$ for the same area is less than $1 \mathrm{~K}$. However, anviltype cirrus clouds, which are commonly found in the decaying stage of the DCC lifetime, can meet the DCC thresholds because of low CTT and smooth cloud morphology by the lateral spreading of DCCs. When applying the DCC method to MODIS visible channel measurements, less than $10 \%$ of total selected DCC targets show larger than $5 \%$ of calibration errors, probably because of unintended targets such as optically thinner anvil-type cirrus $(\mathrm{COT}<100)$ or optically very thick cloud (COT>400) - Sohn et al. (2009). However, those relatively large errors are mostly smoothed out once daily averaging is taken, showing an accuracy better than $5 \%$ 
(a) CS1
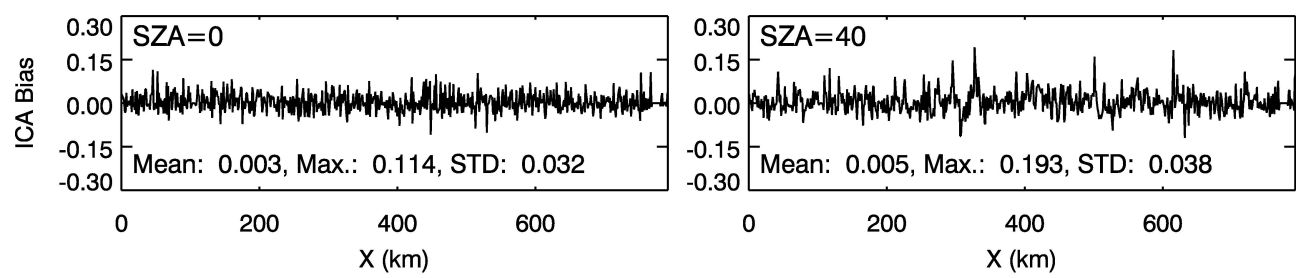

(b) CS2
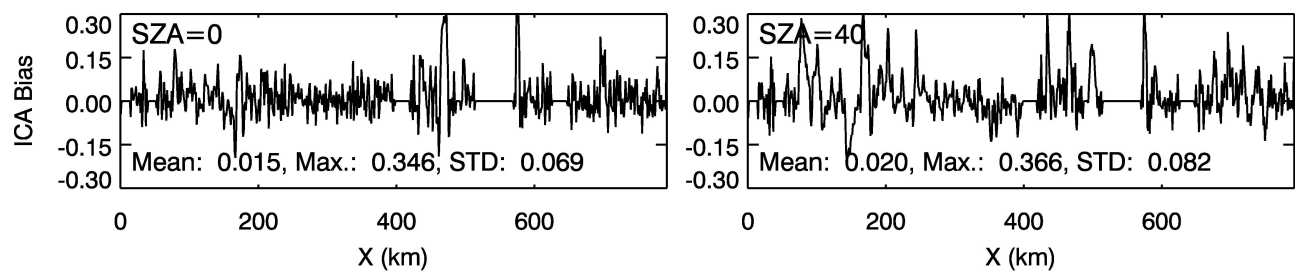

(c) $\mathrm{CS} 3$
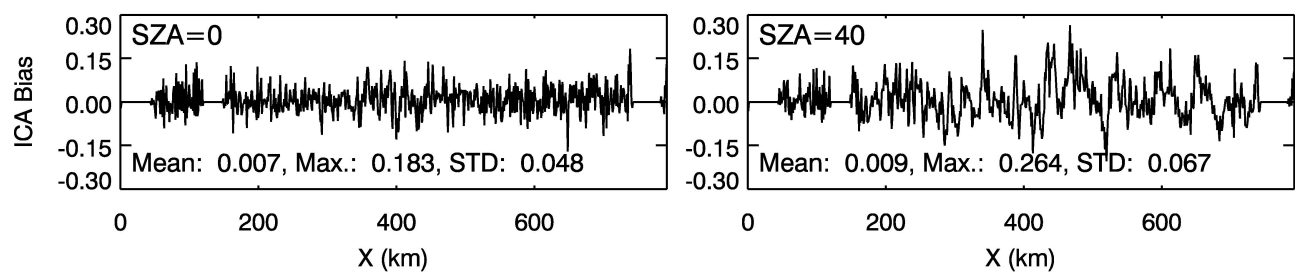

(d) $\mathrm{CS} 4$
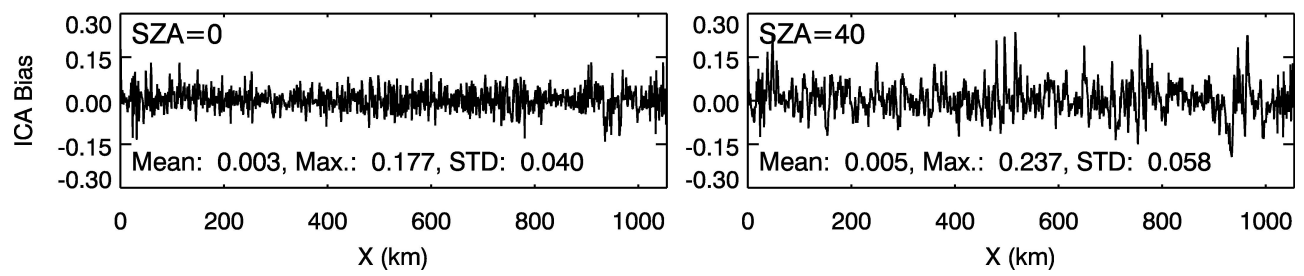

Fig. 6. ICA biases for (a) CS1, (b) CS2, (c) CS3, and (d) CS4. Two SZAs of $0^{\circ}$ and $40^{\circ}$ are considered for each case.

on a daily basis. Therefore, we expect that anvil-type cirrus or cloud edges would not produce systematic biases in the calibration results of Meteosat-8/9 and MTSAT-1R visible channels.

The method of Sohn et al. (2009) summarized above is adopted to calibrate SEVIRI and MTSAT-1R visible channels in this study. Because of the larger footprint of the SEVIRI observations $(\sim 3 \mathrm{~km})$ compared to that of MODIS $(\sim 1 \mathrm{~km})$, a $3 \times 3$-pixel area is used to ensure the homogeneity of selected DCCs. When the homogeneity is satisfied, the center pixel is used as a calibration target. In the case of MTSAT-1R measurements, there are $4 \times 4$ visible pixels within one IR pixel due to different spatial resolutions between visible $(\sim 1 \mathrm{~km})$ and IR $(\sim 4 \mathrm{~km})$ channels. Therefore, if one IR pixel satisfies the condition of $\mathrm{TB}_{11} \leq 190 \mathrm{~K}$, only the middle $2 \times 2$ visible pixels within one IR pixel are used to obtain the measured MTSAT-1R visible channel reflectance of the DCC target, which is then compared with simulated reflectance. For the homogeneity check, a $3 \times 3$ IR pixel area surrounding a chosen IR pixel is used to examine the STD of
$\mathrm{TB}_{11}$. The STD of the visible reflectance is also calculated from the middle $10 \times 10$ visible pixels surrounding the chosen IR pixel. Note that the same thresholds (i.e., $1 \mathrm{~K}$ for STD of $\mathrm{TB}_{11}$ and 0.03 for STD of visible reflectance normalized by its mean) are applied for the homogeneity checks despite different numbers of surrounding pixels used for calculating the STD.

Once DCC targets are selected, ice cloud phase is assumed since the uppermost part of clouds overshooting the TTL mostly contains nonspherical ice particles. In addition, for the radiative transfer simulation for DCCs, their COT and effective radius are assumed to be 200 and $20 \mu \mathrm{m}$, respectively. It is noteworthy to emphasize that MODIS data are not used in Method 3 at all, although a priori conditions of COT and effective radius based on MODIS observations are used for the simulation (Sohn et al., 2009). In addition, cloud layer is assumed to locate between $1 \mathrm{~km}$ and $15 \mathrm{~km}$, based on the fact that overshooting clouds are thicker than $10 \mathrm{~km}$ (Chung et al., 2008; Luo et al., 2008). Expecting insignificant influence of the atmosphere and surface on the DCC simulation, standard 

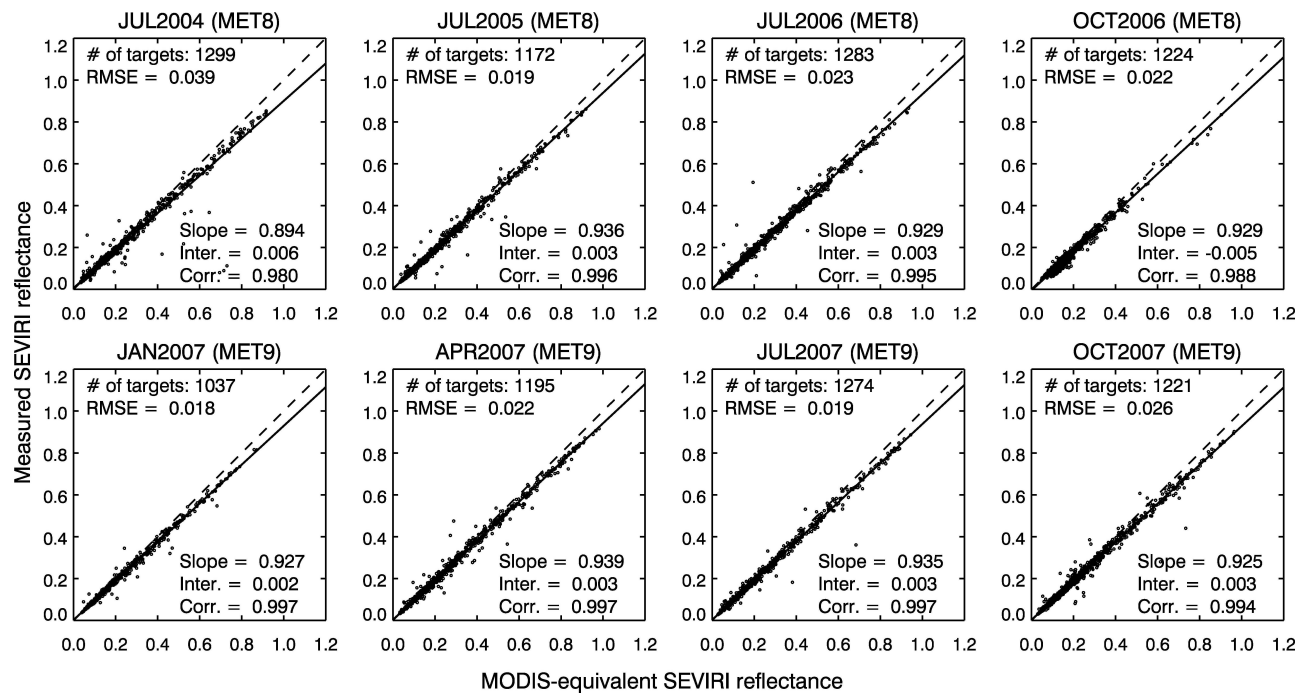

MODIS-equivalent SEVIRI reflectance

Fig. 7. Scatter plots of MODIS-equivalent SEVIRI vs. measured SEVIRI 0.640- $\mu$ m channel reflectances of (top) Meteosat-8 and (bottom) Meteosat-9 from Method 1. Regression lines are given as black solid lines along with associated statistics. Dashed lines represent perfect matches.
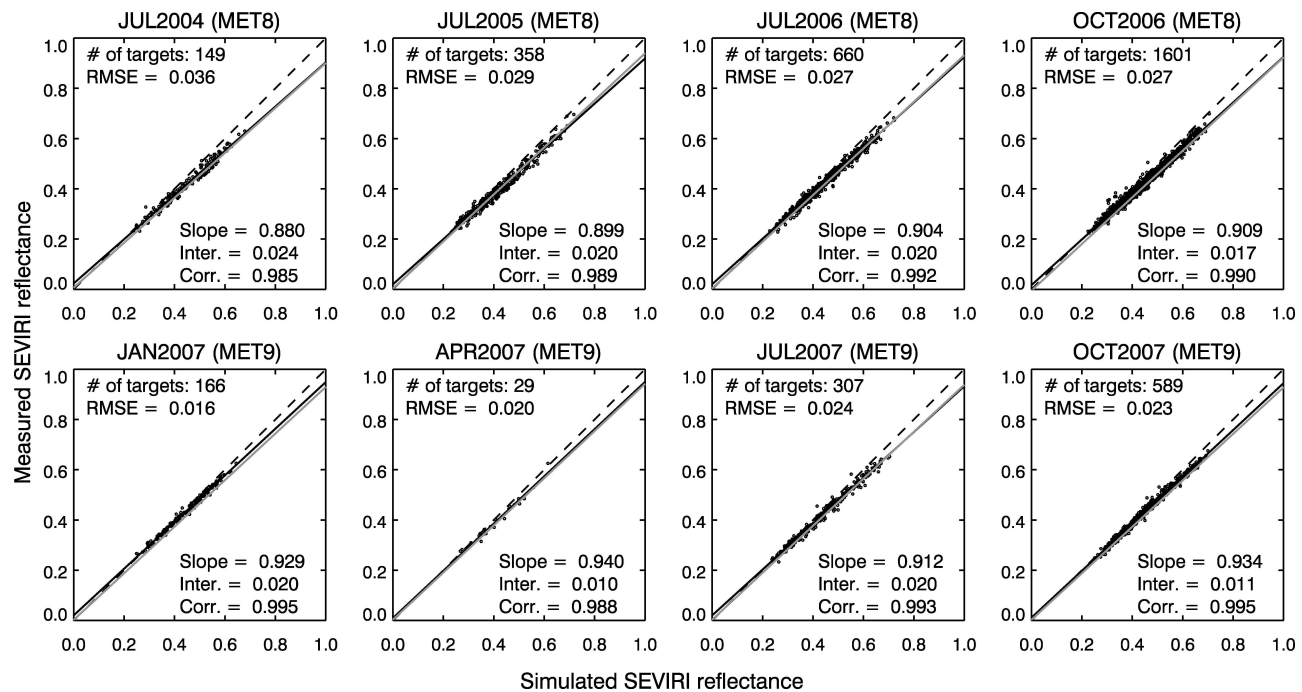

Fig. 8. Scatter plots of simulated vs. measured SEVIRI 0.640- $\mu$ m channel reflectances of (top) Meteosat- 8 and (bottom) Meteosat-9 from Method 2. The simulation is performed for cloud targets using collocated MODIS cloud products. Linear regression results are displayed as black solid lines along with associated statistics. Regression lines from Method 1 are also displayed as grey solid lines.

tropical atmospheric profiles and oceanic BRDF model are used, same as in Methods 1 and 2. Note that DCC targets are collected regardless of the land surface types, even though the oceanic BRDF model is used for the calculation of surface reflectance. Sohn et al. (2009) demonstrated that visible channel simulations can be achieved within an uncertainty of 5\% using these fixed RTM conditions over DCC targets.

The SBDART RTM implemented with 20 streams is used to calculate the visible channel reflectances of DCC targets, which may result in simulation biases by 3-D effects, similar to Method 2. As demonstrated in Sect. 2.2, PPH bias is produced by a nonlinear relationship between COT and reflectance. However, considering that the nonlinearity of reflectance mostly vanishes in the range of COT $>100$, the PPH assumption appears to introduce only minor errors in the DCC simulation. Moreover, DCC targets of SEVIRI and MTSAT-1R are smaller than $0.05^{\circ}$; therefore, PPH biases are negligible once homogeneous targets are chosen (see Fig. 4). The homogeneity conditions of $\operatorname{STD}\left(R_{0.6}\right) /$ Mean $\left(R_{0.6}\right) \leq 0.03$ and $\operatorname{STD}\left(\operatorname{TB}_{11}\right) \leq 1 \mathrm{~K}$ certainly help choosing those types of clouds. ICA biases may also influence DCC calibration results; however, ICA biases can be 
Table 2. Mean, maximum (Max.), and standard deviation (STD) of ICA biases for CS1, CS2, CS3, and CS4 after averaging 50 pixels $(\sim 55 \mathrm{~km})$.

\begin{tabular}{lcrrrr}
\hline Solar Geometry & Value & CS1 & CS2 & CS3 & CS4 \\
\hline SZA $=0^{\circ}$ & Mean & 0.003 & 0.013 & 0.006 & 0.003 \\
& Max. & 0.010 & 0.042 & 0.022 & 0.017 \\
& STD & 0.005 & 0.012 & 0.006 & 0.006 \\
SZA $=20^{\circ}$ & Mean & 0.006 & 0.015 & 0.008 & 0.005 \\
SAA $=90^{\circ}$ & Max. & 0.011 & 0.044 & 0.050 & 0.019 \\
& STD & 0.004 & 0.019 & 0.013 & 0.007 \\
SZA $=20^{\circ}$ & Mean & 0.005 & 0.013 & 0.009 & 0.006 \\
$\mathrm{SAA}=270^{\circ}$ & Max. & 0.011 & 0.039 & 0.029 & 0.036 \\
& STD & 0.004 & 0.013 & 0.008 & 0.009 \\
$\mathrm{SZA}=40^{\circ}$ & Mean & 0.005 & 0.017 & 0.008 & 0.005 \\
$\mathrm{SAA}=90^{\circ}$ & Max. & 0.022 & 0.070 & 0.075 & 0.027 \\
& STD & 0.007 & 0.030 & 0.022 & 0.015 \\
$\mathrm{SZA}=40^{\circ}$ & Mean & 0.005 & 0.008 & 0.011 & 0.007 \\
$\mathrm{SAA}=270^{\circ}$ & Max. & 0.013 & 0.059 & 0.039 & 0.058 \\
& STD & 0.007 & 0.026 & 0.020 & 0.016 \\
$\mathrm{SZA}=60^{\circ}$ & Mean & 0.001 & 0.011 & -0.001 & -0.001 \\
$\mathrm{SAA}=90^{\circ}$ & Max. & 0.034 & 0.084 & 0.103 & 0.036 \\
& STD & 0.013 & 0.043 & 0.039 & 0.030 \\
$\mathrm{SZA}=60^{\circ}$ & Mean & 0.001 & -0.007 & 0.006 & 0.004 \\
$\mathrm{SAA}=270^{\circ}$ & Max. & 0.020 & 0.090 & 0.061 & 0.068 \\
& STD & 0.014 & 0.052 & 0.045 & 0.028 \\
\hline
\end{tabular}

effectively minimized by temporal averaging, homogeneity checks with STD of visible reflectances and $\mathrm{TB}_{11}$, and the use of overcast clouds under relatively smaller SZAs $\left(\leq 40^{\circ}\right)$. In this study, daily averaging is performed only if the number of selected DCC targets is greater than 10 per day.

\section{Results}

\subsection{Meteosat-8/9 SEVIRI 0.640- $\mu \mathrm{m}$ visible channels}

The measurements of SEVIRI $0.640-\mu \mathrm{m}$ channels aboard Meteosat- 8 and -9 are compared against MODIS 0.646- $\mu \mathrm{m}$ channel measurements by applying Method 1. MODISequivalent SEVIRI 0.640- $\mu \mathrm{m}$ channel reflectances are obtained by applying Eqs. (1)-(4). Regardless of the season, all collocated targets are selected from the area of $40^{\circ} \mathrm{W}-$ $40^{\circ} \mathrm{E}$ and $20^{\circ} \mathrm{N}-20^{\circ} \mathrm{S}$, satisfying smaller SZA $\left(\leq 40^{\circ}\right)$, VZA $\left(\leq 40^{\circ}\right)$, and imposed conditions for the ray-matching. In Fig. 7, comparison is made for each month between measured SEVIRI and MODIS-equivalent SEVIRI reflectances. Their associated regression lines are presented as black solid lines, and corresponding regression statistics and the number of used targets are given in the plots. The number of chosen targets is greater than 1000 for each month and scattered patterns generally cover most of reflectances ranging from 0 to 1 . The regression slopes are between 0.894 and 0.936 for Meteosat-8 (four upper panels of Fig. 7) and between 0.925 and 0.939 for Meteosat-9 (four bottom panels of Fig. 7), while intercepts are nearly zero $(<0.01)$ for both Meteosat- 8 and Meteosat-9. No significant difference is noted between Meteosat- 8 and Meteosat-9. Obtained regression slopes except for July 2004 are in the range of $0.93-0.94$ with near zero intercepts, corresponding to 6-7\% of low bias of SEVIRI measurements against MODIS measurements.

The calibration results of Meteosat-8/9 visible channels from Method 1 are quite similar to the results from other previous studies based on the ray-matching technique. Doelling et al. (2004) showed that MODIS 0.646- $\mu \mathrm{m}$ channel radiances were $8 \%$ larger than Meteosat-8 $0.640-\mu \mathrm{m}$ channel radiances. In addition, Jan Fokke Meirink at KNMI (personal communication, 2009) compared SEVIRI and MODIS visible channels after the atmospheric correction, showing $7 \%$ (6\%) larger MODIS 0.646- $\mu \mathrm{m}$ channel reflectances than Meteosat-8 (Meteosat-9) 0.640- $\mu \mathrm{m}$ channel reflectances. All these results commonly assert low biases of SEVIRI 0.640$\mu \mathrm{m}$ channel measurements, implying that the operational calibration of Meteosat visible channels using ocean and desert targets (Govaerts et al., 2004) may underestimate the visible channel reflectances.

Meteosat-8/9 SEVIRI 0.640- $\mu \mathrm{m}$ channel reflectances are simulated using MODIS cloud products as inputs to an RTM, and these serve as references for examining SEVIRI 0.640$\mu \mathrm{m}$ channel measurements (Method 2). In the simulation, only water cloud targets are used to minimize simulation errors associated with nonspherical cloud particles. In Fig. 8, comparisons are made between simulated and measured SEVIRI $0.640-\mu \mathrm{m}$ channel reflectances for each month. Because of the applied threshold of COT $\geq 5$ for selecting cloudonly targets, reflectances smaller than 0.2 are not present in the plots. In general, selected target numbers are smaller than those used for Method 1, and larger temporal variations in the numbers are noted (e.g., as a worst case only 29 targets are available during April 2007). This is because overcast clouds of COT $\geq 5$ are not much abundant over the Atlantic ocean, while those clouds are generally shown along the Intertropical Convergence Zone (ITCZ) located over the African continent. In Fig. 8, regression lines are given as black solid lines, and their associated statistics are also provided. Regression slopes are between 0.880 and 0.909 for Meteosat- 8 (four upper panels of Fig. 8), and between 0.912 and 0.940 for Meteosat-9 (four bottom panels of Fig. 8), while regression intercepts are around 0.02 for both satellites. Regression slopes for Meteosat- 8 are generally smaller than those for Meteosat-9, but the differences are not statistically confident because of insufficient cloud targets for certain months (e.g., July 2004, January 2007, and April 2007). In Fig. 8, regression lines from Method 1 are also given as grey solid lines for comparing with Method 2 (black solid lines). Although Method 2 generally produces smaller slopes and larger intercepts than Method 1, black and grey lines are mostly overlaid with each other for overall periods. Decreased slopes in Method 2 seem to be counterbalanced with increased intercepts. Therefore, it is concluded that Method 2 also provides a similar degree (6-7\%) of low measurement biases of 
(a) Meteosat-8 $0.640 \mu \mathrm{m}$

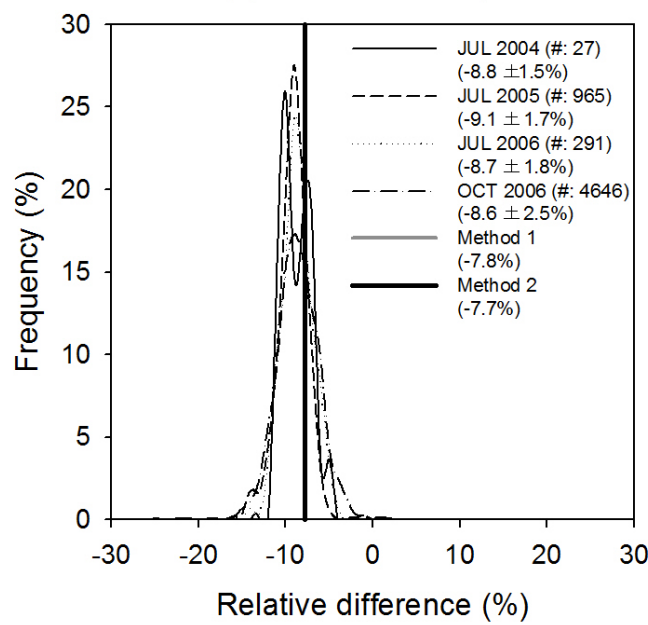

(b) Meteosat-9 $0.640 \mu \mathrm{m}$

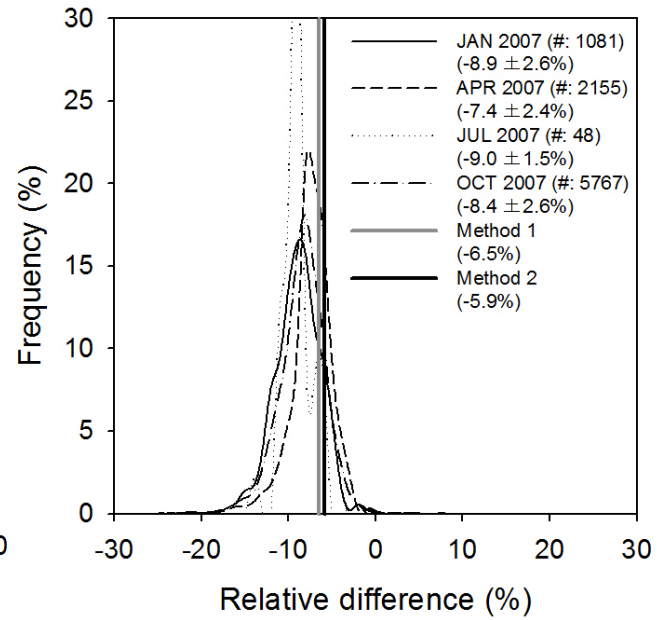

Fig. 9. Monthly frequency histograms of relative differences between measured and simulated reflectances for SEVIRI 0.640- $\mu$ m channel of (a) Meteosat-8 and (b) Meteosat-9 from Method 3. The difference is calculated at each DCC pixel, from which monthly histogram is obtained. The number of DCC pixels used for each month is given in brackets (e.g., 27 pixels are used for July 2004) of the legend, and monthly mean and standard deviation of the differences are given below the number of pixels (e.g., mean and standard deviation of July 2004 are $-8.8 \%$ and $1.5 \%$, respectively). For the comparison of three methods, mean biases inferred from Methods 1 and 2 are also given with grey and black vertical lines, respectively.

Meteosat-8 and Meteosat-9 0.640- $\mu \mathrm{m}$ channels, in comparison to MODIS measurements. Slight differences in regression results between Methods 1 and 2 are likely due to the target reflectances larger than about 0.2 in Method 2, causing larger uncertainties in the regression intercepts. Note that results of Methods 1 and 2 are not displayed separately for Terra and Aqua MODIS. It is because differences between Terra and Aqua are considered to be small compared to the degree of uncertainties of each method, although about $2 \%$ differences between Terra and Aqua can be expected (Minnis et al., 2008).

DCC targets are selected using SEVIRI window channel measurements, and the reference reflectances for those selected DCC targets are produced from simulations with characteristic cloud optical properties (Method 3). We found a bundle of points situated over the simulated reflectance around 1 , hindering the linear regression between simulated and measured SEVIRI reflectances. Instead monthly frequency histograms of relative differences [(measured - simulated)/simulated $\times 100 \%$ ] are provided in Fig. 9. High peaks in frequency are appeared at similar values throughout all periods. Monthly means of the relative differences are from $-9.1 \%$ to $-8.6 \%$ for Meteosat-8 (left panel of Fig. 9), and from $-9.0 \%$ to $-7.4 \%$ for Meteosat-9 (right panel of Fig. 9), implying low measurement biases of SEVIRI 0.640$\mu \mathrm{m}$ channels. In comparison to Method 1 or Method 2 showing $6-7 \%$ of low biases, the degree of biases from Method 3 appears slightly stronger. For the quantitative comparison amongst three methods, we apply regression equations obtained in Methods 1 and 2 to predict measurement biases at the MODIS-equivalent reflectance around 1 where DCC targets are located. From Method $1,-7.8 \%$ and $-6.5 \%$ of Meteosat-8 and Meteosat-9 SEVIRI measurement biases are predicted for DCC targets, respectively. On the other hand, $-7.7 \%$ and $-5.9 \%$ of measurement biases are predicted from Method 2. These predicted biases are displayed with vertical lines in Fig. 9. It is certain that Method 3 produces systematically larger biases by $2-3 \%$, in comparison to results from Method 1 or 2.

In Fig. 10, results from Method 3 are directly compared with results from Methods 1 and 2. Monthly regression lines from Methods 1 and 2 (shown in Figs. 7 and 8) are given as grey and black solid lines, respectively, while Method 3 results are given with crosses. Each cross in Method 3 results represents a daily average. As shown in Fig. 9, crosses are below the two regression lines, and thus the discrepancy of the DCC results from Methods 1 and 2 appears to be evident with orders of 2-3\%. In Sohn et al. (2009), the accuracy of Method 3 is shown to be within a 5\% uncertainty level, and therefore discrepancy of Method 3 from Method 1 or 2 may be attributed to uncertainties in Method 3. However, considering that simulations by the DCC method (Method 3) did not show an apparent bias when applied to the wellcalibrated MODIS visible channel (Sohn et al., 2009), the discrepancy of Method 3 may be interpreted as the saturation characteristics of SEVIRI visible channels when targets are highly reflective (Yves M. Govaerts at EUMETSAT, personal communication, 2010). Similar saturation characteristics were inferred from the inter-satellite calibration results of Jan Fokke Meirink at KNMI (Jan Fokke Meirink, personal communication, 2009), which showed larger biases of Meteosat-8/9 measurements at the high reflectance end. 

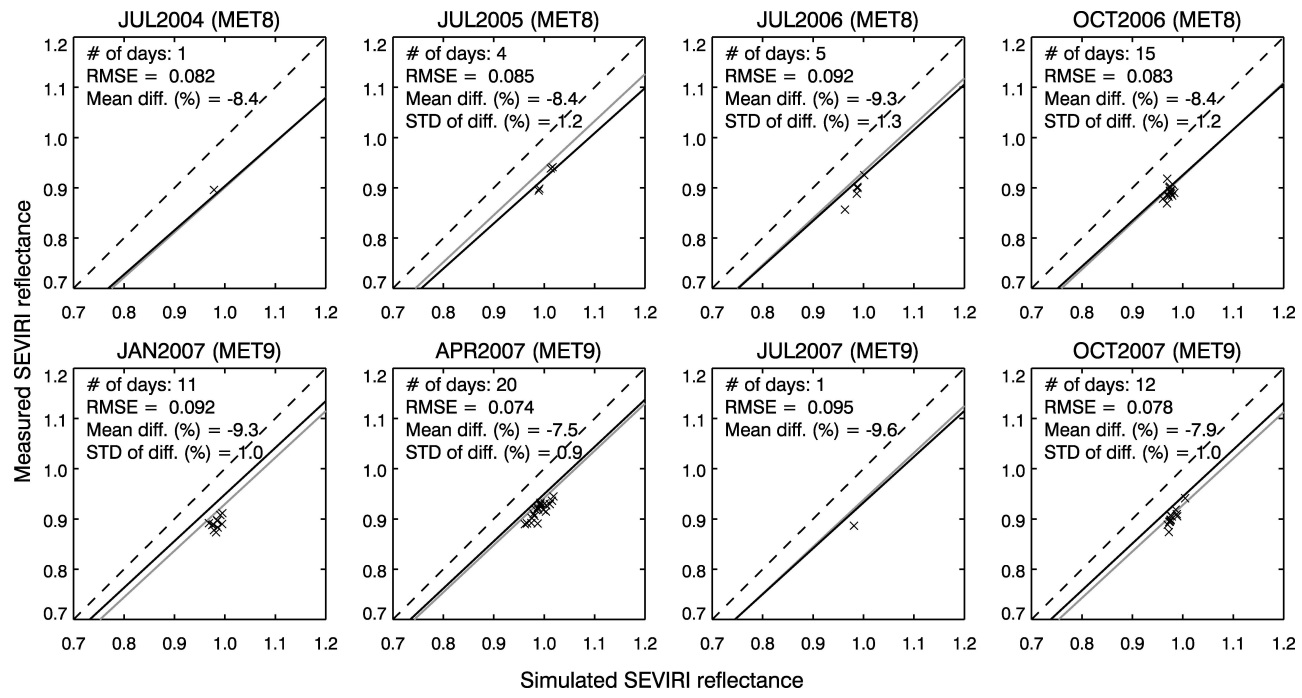

Fig. 10. Comparison of Method 3 (crosses) against Method 1 (grey solid line) and Method 2 (black solid line) for (top) Meteosat-8 and (bottom) Meteosat-9 SEVIRI 0.640- $\mu$ m channels. For Method 3, the daily average is calculated when the number of selected DCC targets is greater than 10. On a daily basis, differences between measured and simulated reflectances are calculated and their monthly mean and standard deviation are given on each panel. Dashed lines are perfect matches.
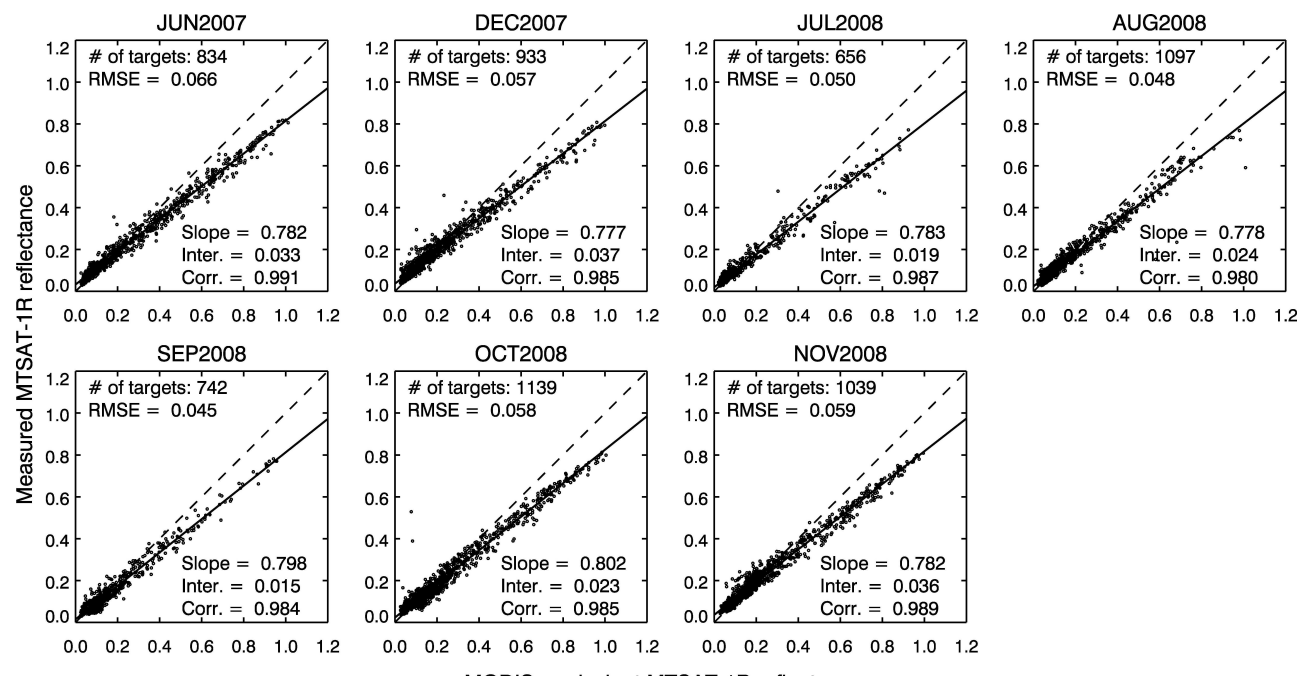

$\begin{array}{lllllll}0.0 & 0.2 & 0.4 & 0.6 & 0.8 & 1.0 & 1.2\end{array}$

MODIS-equivalent MTSAT-1R reflectance

Fig. 11. Same as in Fig. 7 but for the MTSAT-1R 0.724- $\mu$ m channel (Method 1).

However, a more detailed explanation appears to be beyond the current research scope and thus deserves a separate examination.

\subsection{MTSAT-1R visible channel}

MTSAT-1R 0.724- $\mu \mathrm{m}$ channel measurements are compared to MODIS $0.646-\mu \mathrm{m}$ channel measurements using the raymatching technique (Method 1). Throughout the sevenmonth period, all collocated targets are shown to be located in the area of $100^{\circ} \mathrm{E}-180^{\circ} \mathrm{E}, 20^{\circ} \mathrm{N}-20^{\circ} \mathrm{S}$. For the chosen targets, measured MODIS channel reflectances are converted to MODIS-equivalent MTSAT-1R reflectances using Eqs. (5) and (6), and these converted MODIS-equivalent reflectances are compared with measured MTSAT-1R reflectances (Fig. 11). In comparison to the SEVIRI results (Fig. 7), the MTSAT-1R 0.724- $\mu \mathrm{m}$ channel exhibits a more scattered pattern. This is probably due to the scan method of JAMI (David R. Doelling of NASA Langley, personal communication, 2010). Moreover, if MTSAT-1R wobbles from the nominal position $\left(140^{\circ} \mathrm{E}, 0^{\circ} \mathrm{N}\right)$, then the viewing geometry at each pixel point is correspondingly changed from the nominal value, causing uncertainties in the ray-matching process. On a monthly basis, linear regression results in slopes 

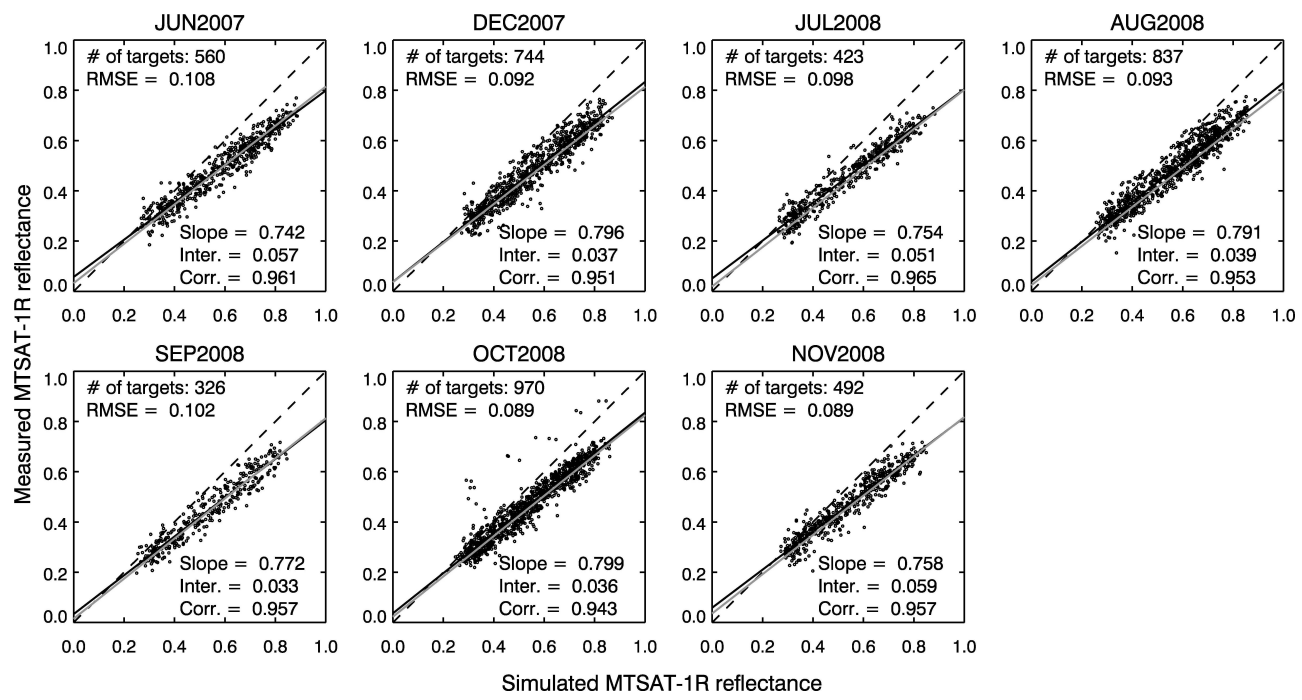

Fig. 12. Same as in Fig. 8 but for the MTSAT-1R 0.724- $\mu$ m channel (Method 2).

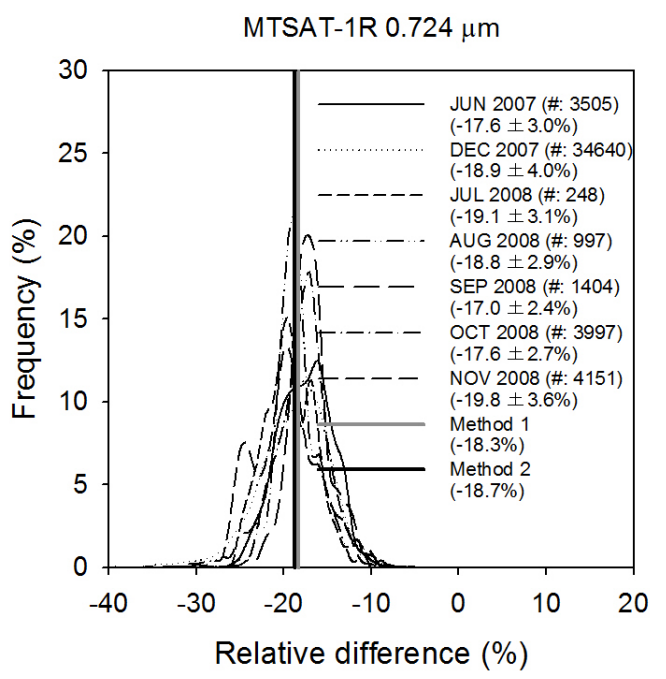

Fig. 13. Same as in Fig. 9 but for the MTSAT-1R 0.724- $\mu \mathrm{m}$ channel (Method 3).

between 0.777 and 0.802 , and intercepts between 0.015 and 0.037. The slopes are much smaller than 1. Furthermore, intercept off the zero causes the calibration uncertainty depending on the magnitude of reflectance. Bias should be positive when reflectance is small, for example in case of reflectance $<0.15$. In contrast, underestimate of calibrated reflectance is shown when the reflectance becomes larger, resulting in about $20 \%$ of underestimate at the high end of MODIS-equivalent reflectance.

MTSAT-1R 0.724- $\mu \mathrm{m}$ channel reflectances are simulated with MODIS cloud products, and the simulation results are used to examine MTSAT-1R measurements (Method 2). Since low cloud occurrences are not frequent enough for the calibration in the analysis domain $\left(100^{\circ} \mathrm{E}-180^{\circ} \mathrm{E}, 40^{\circ} \mathrm{N}-\right.$ $40^{\circ} \mathrm{S}$ ), abundant high cloud targets containing ice cloud particles are included in Method 2 analysis. In the process, more than 300 calibration targets are collected for each month. Compared to Meteosat-8/9 results (Fig. 8), a larger degree of scatterings is noted between simulated and measured reflectances - Fig. 12. Again, this may be due to scan problems of MTSAT-1R as well as simulation uncertainties of ice cloud targets related to nonspherical habits. In spite of the large scattering, measured reflectances are linearly correlated with simulated reflectances, showing regression slopes of $0.742-0.799$, and intercepts of $0.033-0.059$. These results are consistent with those obtained from Method 1, showing a near agreement between two regression lines (i.e. grey line vs. black line shown in each diagram of Fig. 12). Therefore, Method 2 also suggests an underestimate of calibrated reflectance up to $20 \%$ at the high end of reflectance and incorrect space count offset of the MTSAT-1R calibration.

These results are consistent with Okuyama (2009) results based on ocean-desert-cloud combined targets, in which the regression slope between simulated and measured reflectances was around 0.8. However, Okuyama (2009) showed a near-zero intercept offset, significantly different from offset results from both Method 1 and Method 2, probably because of more uncertain parameterization of dark ocean targets.

MTSAT-1R visible channel reflectances simulated over DCC targets using Method 3 are compared with measured reflectances. Monthly frequency distributions of the relative differences of measured reflectances are plotted against simulation results in Fig. 13 [(measured - simulated)/simulated $\times 100 \%$ ]. Although much broader frequency distributions are found compared to SEVIRI visible channels (Fig. 9), their peaks are appeared at similar values over the analysis period, suggesting that results are not much variant over 

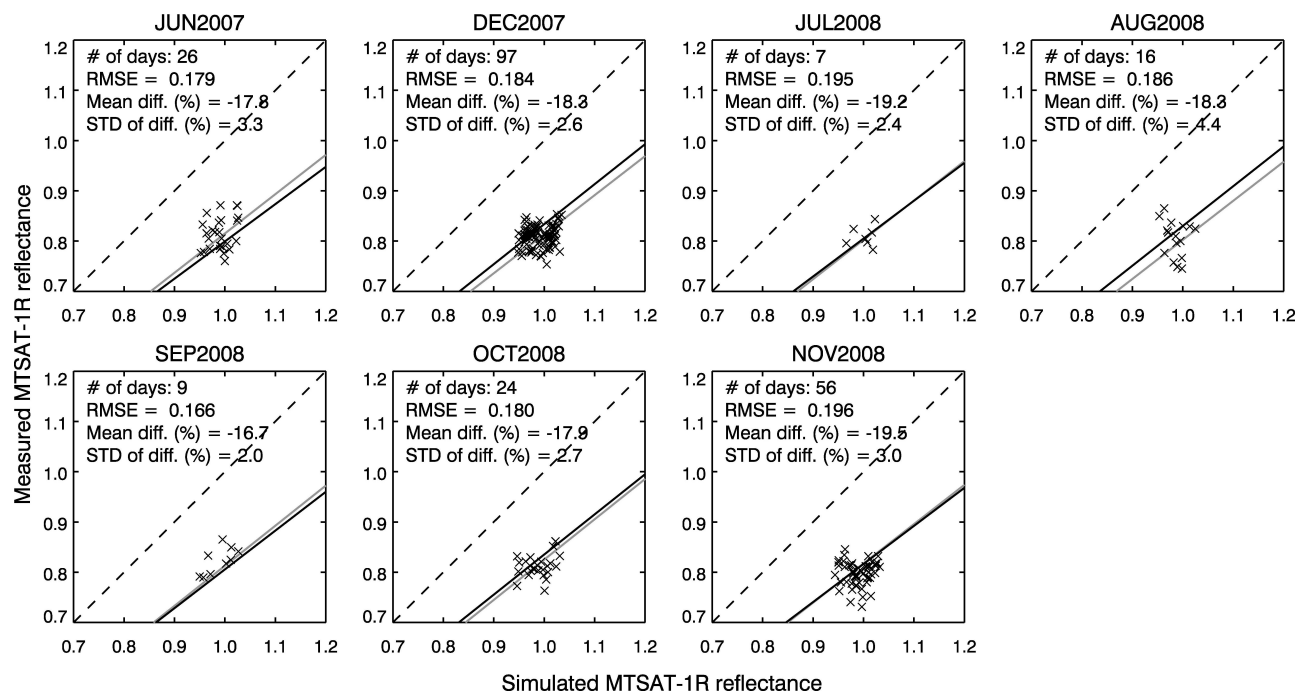

Fig. 14. Same as in Fig. 10 but for the MTSAT-1R 0.724- $\mu \mathrm{m}$ channel.

the time. Resultant monthly mean differences ranging from $-19.8 \%$ to $-17.0 \%$ are in line with biases predicted from Methods 1 and 2; MTSAT-1R measurement biases at a unit reflectance were calculated to be $-18.3 \%$ and $-18.7 \%$ from Methods 1 and 2, respectively - find seven month mean biases expressed as vertical grey and black lines in Fig. 13. Differences should be small amongst Methods 1, 2, and 3 because the mean position of high peaks of histograms is located near the vertical grey and black lines.

In Fig. 14, results from Method 3 are compared with those from Methods 1 and 2 using scatter plots. Again results indicate that DCC results are in near agreement with what predicted from two regression results, suggesting the measurement biases of MTSAT-1R visible channel to be between $-19.5 \%$ and $-16.7 \%$ around a unit reflectance. The consistency found amongst MTSAT-1R results from Methods 1, 2 , and 3 strongly suggests that the $2 \%$ stronger bias by the Method 3 in the SEVIRI results should not be due to the deficiency of Method 3, but due to the saturation of the sensor capability of detecting the high side of reflectance. Furthermore, it is suggested that the large scattered patterns found in MTSAT-1R results from Methods 1 and 2 [i.e., two or three times larger root mean square error (RMSE) compared to RMSE of Meteosat-8/9] are not likely due to the water vapor absorption around $0.724 \mu \mathrm{m}$. It is because the DCC results showing the same degree of scattering should not be sensitive to the water vapor absorption, as seen in the comparison between Fig. 10 and Fig. 14.

\section{Summary}

In this paper we examined the performance of operational calibration of Meteosat-8/9 SEVIRI 0.640- $\mu \mathrm{m}$ and MTSAT1R $0.724-\mu \mathrm{m}$ visible channels using three calibration meth- ods. The first method is based on the ray-matching technique for inter-satellite calibration. MODIS $0.646-\mu \mathrm{m}$ channel is used as a reference, and reflectances are compared between MODIS and SEVIRI, and MODIS and MTSAT-1R only over oceanic regions. Regression equations are obtained from radiative transfer simulations to convert measured MODIS reflectances into MODIS-equivalent SEVIRI or MTSAT-1R channel reflectances. The results obtained from the raymatching technique indicate that SEVIRI calibration coefficient is biased low by 6-7\%. On the other hand, MTSAT-1R calibration errors appear to vary with the magnitude of reflectance itself because of the incorrect space offset count; a positive bias near zero reflectance turns into negative bias up to $-20 \%$ in case of reflectance around 1.0 .

The Meteosat-8/9 and MTSAT-1R channel reflectances are simulated using collocated MODIS cloud products, such as COT, particle effective radius, CTT, and CTP as inputs for the radiative transfer model. In the simulation, the LN-ICA method (Oreopoulos and Davies, 1998b) is adopted to describe the subgrid variability because the plane-parallel assumption at each grid box could generate simulation errors by 3-D radiative effects. Horizontal radiative interaction appears to be negligible as a result of $0.5^{\circ}$-grid spatial averaging, homogeneity checks $\left[\operatorname{STD}\left(R_{0.6}\right) \leq 0.1\right]$, and the use of overcast clouds under moderate SZAs $\left(\leq 40^{\circ}\right)$. Suggested biases in Meteosat-8/9 and MTSAT-1R visible channel calibration appear to be consistent with results from the raymatching technique since regression results from two methods are mostly overlapped. This implies that 3-D effects are effectively taken into account from the LN-ICA method because the Method 2 gives consistent results with results derived from MODIS radiance observations (i.e. Method 1). However, it should be noted that performances of Methods 1 and 2 can be related to each other since cloud products 
used for Method 2 are retrieved from the same radiances as used for Method 1.

Results from these two methods are compared with those derived from the DCC method. It is suggested that Meteosat8/9 measurements may not be sensitive enough to discretize the reflectance when targets are highly reflective, suggesting a saturation of measured radiances. In contrast, there is no particular pattern showing the saturation for the MTSAT$1 \mathrm{R}$ visible channel as shown in two regression lines going through a bundle of DCC-derived points.

Overall, all three calibration methods show an agreement within 2-3\% and suggest that the current Meteosat-8/9 SEVIRI $0.640-\mu \mathrm{m}$ channels underestimate reflectances by $6-$ $9 \%$. It is also noted that the current MTSAT-1R visible sensor may be subject to biases, depending on the reflectance ranging from $+5 \%$ at near 0.1 to $-20 \%$ at near 1.0 . Further study is required to examine why the MTSAT-1R shows a diverse error range depending on the target reflectance.

Acknowledgements. We thank four anonymous reviewers for their constructive and valuable comments, which led to an improved version of the paper. We convey sincere thanks to Yves M. Govaerts and Johannes Schmetz at EUMETSAT for sharing views on the vicarious calibration and for providing satellite data used in this study. This work was supported by the NSL (National Space Lab) program through the National Research Foundation of Korea (S10801000184-08A0100-18410), and by the BK21 Program of the Korean Government.

Edited by: B. Mayer

\section{References}

Arriaga, A. and Schmetz, J.: Calibration of the Meteosat-5/-6 VIS Channels with help of modeled Radiances, Contrib. Atmos. Physics, 72, 133-139, 1999.

Barker, H. W.: A parameterization for computing grid-averaged solar fluxes for inhomogeneous marine boundary layer clouds. Part I: Methodology and homogeneous biases, J. Atmos. Sci., 53, 2289-2303, 1996.

Barnes, W. L., Pagano, T. S., and Salomonson, V. V.: Prelaunch characteristics of the Moderate Resolution Imaging Spectroradiometer (MODIS) on EOS-AM1, IEEE T. Geosci. Remote S., 36, 1088-1100, 1998.

Barnes, R. A., Barnes, W. L., Lyu, C.-H., and Gales, J. M.: An overview of the visible and infrared scanner radiometric calibration algorithm, J. Atmos. Oceanic Tech., 17, 395-405, 2000.

Baum, B. A., Heymsfield, A. J., Yang, P., and Bedka, S. T.: Bulk scattering properties for the remote sensing of ice clouds. Part I: Microphysical data and models, J. Appl. Meteorol., 44, 18851895, 2005a.

Baum, B. A., Yang, P., Heymsfield, A. J., Platnick, S., King, M. D., Hu, Y.-X., and Bedka, S. T: Bulk scattering properties for the remote sensing of ice clouds. Part II: Narrowband models, J. Appl. Meteorol., 44, 1896-1911, 2005 b.

Baum, B. A., Yang, P., Nasiri, S, Heidinger, A. K., Heymsfield, A. J., and Li, J.: Bulk scattering properties for the remote sensing of ice clouds. Part III: High resolution spectral models from 100 to $3250 \mathrm{~cm}^{-1}$, J. Appl. Meteorol. Clim., 46, 423-434, 2007.

Bruegge, C. J., Duval, V. G., Chrien, N. L., Korechoff, R. P., Gaitley, B. J., and Hochberg, E. B.: MISR prelaunch instrument calibration and characterization results, IEEE T. Geosci. Remote S., 36, 1186-1198, 1998.

Cahalan, R. F., Ridgway, W., Wiscombe, W. J., Bell, T. L., and Snider, J. B.: The albedo of fractal stratocumulus clouds, J. Atmos. Sci., 51, 2434-2455, 1994a.

Cahalan, R. F., Ridgway, W., Wiscombe, W. J., Gollmer, S., and Harshvardhan: Independent pixel and Monte Carlo estimates of stratocumulus albedo, J. Atmos. Sci., 51, 3776-3790, 1994b.

Calin, B., Fu, Q., Lohmann, U., Mace, G. G., Sassen, K., and Comstock, J. M.: High-cloud horizontal inhomogeneity and solar albedo bias, J. Climate, 15, 2321-2339, 2002.

Chung, E.-S., Sohn, B. J., and Schmetz, J.: CloudSat shedding new light on high-reaching tropical deep convection observed with Meteosat, Geophys. Res. Lett., 35, L02814, doi:10.1029/2007GL032516, 2008.

Deneke, H. M. and Roebling, R.: Downscaling of METEOSAT SEVIRI 0.6 and 0.8 micron channel radiances utilizing the highresolution visible channel, Atmos. Chem. Phys. Discuss., 10, 10707-10740, doi:10.5194/acp-10-10707-2010, 2010.

Doelling, D., Nguyen, L., and Minnis, P.: Calibration comparisons between SEVIRI, MODIS, and GOES data, EUMETSAT Meteorological Satellite Conference, Prague, Czech Republic, 77-83, 2004.

Fraser, R. S. and Kaufman, Y. J.: Calibration of satellite sensors after launch, Appl. Opt., 25, 1177-1185, 1986.

Govaerts, Y. M. and Clerici, M.: Evaluation of radiative transfer simulations over bright desert calibration sites, IEEE T. Geosci. Remote S., 42, 176-187, 2004.

Govaerts, Y. M., Arriaga, A., and Schmetz, J.: Operational vicarious calibration of the MSG/SEVIRI solar channels, Adv. Space. Res., 28, 21-30, doi:10.1016/S0273-1177(01)00269-1, 2001.

Govaerts, Y. M., Clerici, M., and Clerbaux, N.: Operational calibration of the Meteosat radiometer VIS band, IEEE T. Geosci. Remote S., 42, 1900-1914, 2004.

Govaerts, Y. M., Wagner, S., Clerici, M.: SEVIRI native format pre-processing toolbox user's guide, Issue: SPT Version 2.4, No: EUM/OPS-MSG/TEN/03/0011, EUMETSAT, Darmstadt, Germany, 2006.

Ham, S.-H., Sohn, B. J., Yang, P., and Baum, B. A.: Assessment of the quality of MODIS cloud products from radiance simulations, J. Appl. Meteorol. Clim., 48, 1591-1612, 2009.

Heidinger, A. K., Cao, C., and Sullivan, J. T.: Using Moderate Resolution Imaging Spectrometer (MODIS) to calibrate advanced very high resolution radiometer reflectance channels, J. Geophys. Res., 107, 4702, doi:10.1029/2001JD002035, 2002.

Heymsfield, A. J., Bansemer, A., Field, P. R., Durden, S. L., Stith, J. L., Dye, J. E., Hall, W., and Grainger, C. A.: Observations and parameterizations of particle size distributions in deep tropical cirrus and stratiform precipitating clouds: Results from in situ observations in TRMM field campaigns, J. Atmos. Sci., 59, 3457-3491, 2002.

House, L. L. and Avery, L.W.: The Monte Carlo technique applied to radiative transfer, J. Quant. Spectrosc. Rad., 9, 1579-1591, 1969.

Hu, Y.-X., Wielicki, B., Lin, B., Gibson, G., Tsay, S.-C., Stamnes, 
K., and Wong, T.: $\delta$-Fit: A fast and accurate treatment of particle scattering phase functions with weighted singular-value decomposition least-squares fitting, J. Quant. Spectrosc. Ra., 65, 681-690, 2000.

Hu, Y.-X., Wielicki, B., Yang, P., Stackhouse Jr., P. W., Lin, B., and Young, D. F.: Application of deep convective cloud albedo observation to satellite-based study of the terrestrial atmosphere: monitoring the stability of spaceborne measurements and assessing absorption anomaly, IEEE T. Geosci. Remote S., 42, 25942599, 2004.

Japan Meteorological Agency: JMA HRIT mission specific implementation, Version 1.2, 59 pp., 2003.

Johnson, B. C., Early, E. A., Eplee Jr., R. E., Barnes, R. A., and Caffrey, R. T.: The 1997 Prelaunch Calibration of SeaWiFS, NASA Tech. Memo. 1999-206892, 58 pp., 1999.

King, M. D.: Number of terms required in the Fourier expansion of the reflection function for optically thick atmospheres, J. Quant. Spectrosc. Rad., 30, 143-161, 1983.

Knapp, K. R. and Vonder Haar, T. H.: Calibration of the eighth Geostationary Observational Environmental Satellite (GOES-8) imager visible sensor, J. Atmos. Oceanic Tech., 17, 1639-1644, 2000.

Kriebel, K. T. and Amann, V.: Vicarious calibration of the Meteosat visible channel, J. Atmos. Oceanic Tech., 10, 225-232, 1993.

Loeb, N. G., Varnai, T., and Winker, D. M.: Influence of subpixelscale cloud-top structure on reflectances from overcast stratiform cloud layers, J. Atmos. Sci., 55, 2960-2973, 1998.

Luo, Z., Liu, G. Y., and Stephens, G. L.: CloudSat adding new insight into tropical penetrating convection, Geophys. Res. Lett., 35, L19819, doi:10.1029/2008GL035330, 2008.

Marchuk, G., Mikhailov, G., Navaraliev, M., Darbinjan, R., Kargin, B., and Elepov, B.: The Monte Carlo Methods in Atmospheric Optics, Spinger-Verlag, 208 pp., 1980.

Marshak, A., Davis, A., Wiscombe, W. J., Ridgway, W., and Cahalan, R. F.: Biases in shortwave column absorption in the presence of fractal clouds, J. Climate, 11, 431-446, 1998.

Martiny, N., Santer, R., and Smolskaia, I.: Vicarious calibration of MERIS over dark waters in the near infrared, Remote Sens. Environ., 94, 475-490, 2005.

Minnis, P., Nguyen, L., Doelling, D. R., Young, D. F., Miller, W. F., and Kratz, D. P.: Rapid calibration of operational and research meteorological satellite imagers. Part I: Evaluation of research satellite visible channels as references, J. Atmos. Oceanic Tech., 19, 1233-1249, 2002a.

Minnis, P., Nguyen, L., Doelling, D. R., Young, D. F., Miller, W. F., and Kratz, D. P.: Rapid calibration of operational and research meteorological satellite imagers. Part II: Comparison of infrared channels, J. Atmos. Oceanic Tech., 19, 1250-1266, 2002 b.

Minnis, P., Doelling, D. R., Nguyen, L., Miller, W. F., and Chakrapani, V.: Assessment of the visible channel calibrations of the VIRS on TRMM and MODIS on Aqua and Terra, J. Atmos. Oceanic Tech., 25, 385-400, 2008.

Nakajima, T. and Tanaka, M.: Algorithm for radiative intensity calculations in moderately thick atmospheres using a truncation approximation, J. Quant. Spectrosc. Ra., 40, 51-69, 1988.

Okuyama, A.: Vicarious calibration of visible channel activity at the JMA, GSICS GRWG-GDWG Joint Meeting, Tokyo, Japan, January 28-30, 2009.

Oreopoulos, L. and Davies, R.: Plane parallel albedo biases from satellite observations. Part I: Dependence on resolution and other factors, J. Climate, 11, 919-932, 1998a.

Oreopoulos, L. and Davies, R.: Plane parallel albedo biases from satellite observations. Part II: Parameterizations for bias removal, J. Climate, 11, 933-944, 1998b.

Pierluissi, J. H. and Peng, G.-S.: New molecular transmission band models for LOWTRAN, Opt. Eng., 24 (3), 541-547, 1985.

Ricchiazzi, P.: Input documentation for SBDART, Univ. of California, Santa Barbra, 2002.

Ricchiazzi, P., Yang, S., Gautier, C., and Sowle, D.: SBDART: A research and teaching software tool for plane-parallel radiative transfer in the Earth's atmosphere, B. Am. Meteorol. Soc., 79, 2101-2114, 1998.

Sakuma, F., Ono, A., Tsuchida, S., Ohgi, N., Inada, H., Akagi, S., and Ono, H.: Onboard calibration of ASTER Instrument, IEEE T. Geosci. Remote S., 43, 2715-2724, 2005.

Scheirer, R. and Macke, A.: Cloud inhomogeneity and broadband solar fluxes, J. Geophys. Res., 108(D19), 4599, doi:10.1029/2002JD003321, 2003.

Schmetz, J., Pili, P., Tjemkes, S., Just, D., Kerkmann, J., Rota, S., and Ratier, A.: An introduction to Meteosat Second Generation (MSG), B. Am. Meteorol. Soc., 83, 977-992, 2002.

Sohn, B. J., Schmetz, J., Tjemkes, S., Koenig, M., Lutz, H., Arriaga, A., and Chung, E.-S.: Intercalibration of the Meteosat7 water vapor channel with SSM/T-2, J. Geophys. Res., 105, 15673-15680, 2000.

Sohn, B. J., Park, H.-S., Han, H.-J., and Ahn, M.-H.: Evaluating the calibration of MTSAT-1R infrared channels using collocated Terra MODIS measurements, Int. J. Remote Sens., 29, 30333042, 2008.

Sohn, B. J., Ham, S.-H., and Yang, P.: Possibility of the visiblechannel calibration using deep convective clouds overshooting the TTL, J. Appl. Meteorol. Clim., 48, 2271-2283, 2009.

Sun, J.-Q., Xiong, X., and Barnes, W. L.: MODIS solar diffuser stability monitor sun view modeling, IEEE T. Geosci. Remote S., 43, 1845-1854, 2005.

Tahara, Y. and Ohkawara, N.: Status of MTSAT-1R and recent activities in MSC, Proc. 2005 EUMETSAT Meteor. Satellite Conf., Dubrovnik, Croatia, EUMETSAT, 9-15, 2006.

Varnai, T.: Influence of three-dimensional radiative effects on the spatial distribution of shortwave cloud reflection, J. Atmos. Sci., 57, 216-229, 2000.

Varnai, T. and Davies, R.: Effects of cloud heterogeneities on shortwave radiation: Comparison of cloud-top variability and internal heterogeneity, J. Atmos. Sci., 56, 4206-4224, 1999.

Vermote, E. and Kaufman, Y. J.: Absolute calibration of AVHRR visible and near-infrared channels using ocean and cloud views, Int. J. Remote Sens., 16, 2317-2340, 1995.

Vermote, E. F. and Saleous, N. Z.: Calibration of NOAA16 AVHRR over a desert site using MODIS data, Remote Sens. Environ., 105, 214-220, 2006.

Vermote, E. F., Member, IEEE, Tanre, D., Deuze, J. L., Herman, M., and Morcrette, J.-J.: Second Simulation of the Satellite Signal in the Solar Spectrum, 6S: An overview, IEEE T. Geosci. Remote S., 35, 675-686, 1997.

Wiscombe, W. J.: The Delta-M Method: Rapid yet accurate radiative flux calculations for strongly asymmetric phase functions, J. Atmos. Sci., 34, 1408-1422, 1977.

Wu, X. and Sun, F.: Post-launch calibration of GOES Imager visible 
channel using MODIS, in: Earth Observing Systems X, edited by: Butler, J. J., International Society for Optical Engineering, SPIE Proc., 5882, doi:10.1117/12.615401, 2005.

Xiong, X. and Barnes, W. L.: Early on-orbit calibration results from Aqua MODIS, in: Sensors, Systems, and Next-Generation Satellites VI, edited by: Fujisada, H., Lurie, J. B., Aten, M. L., et al., International Society for Optical Engineering, SPIE Proc., 4881, 327-336, 2003.

Xiong, X. and Barnes, W. L.: An overview of MODIS radiometric calibration and characterization, Adv. Atmos. Sci., 23, 69-79, 2006.

Yang, P., Liou, K. N., Wyser, K., and Mitchell, D.: Parameterization of the scattering and absorption properties of individual ice crystals, J. Geophys. Res., 105(D4), 4699-4718, doi:10.1029/1999JD900755, 2000.
Yang, P., Baum, B. A., Heymsfield, A. J., Hu, Y.-X., Huang, H.-L., Tsay, S.-C., and Ackerman, S.: Single-scattering properties of droxtals, J. Quant. Spectrosc. Ra., 79-80, 1159-1169, 2003.

Yang, P., Wei, H., Huang, H.-L., Baum, B. A., Hu, Y.-X., Kattawar, G. W., Mishchenko, M. I., and Fu, Q.: Scattering and absorption property database for nonspherical ice particles in the nearthrough far-infrared spectral region, Appl. Opt., 44, 5512-5523, 2005 . 